Article

\title{
Impact of Different Stoppers on the Composition of Red and Rosé Lagrein, Schiava (Vernatsch) and Merlot Wines Stored in Bottle
}

\author{
Fabrizio Rossetti ${ }^{1}\left(\mathbb{D}\right.$, Alicia Jouin ${ }^{2}$, Michael Jourdes ${ }^{2}{ }^{(D}$, Pierre-Louis Teissedre ${ }^{2}{ }^{(}$, \\ Roberta Foligni ${ }^{3}$, Edoardo Longo $4,5, * \mathbb{D}$ and Emanuele Boselli ${ }^{4,5}$ (D) \\ 1 Mérieux NutriSciences, via Marradi 41, 59100 Prato, Italy; fabrizio.rossetti@mxns.com \\ 2 Unité de recherche Enologie, Universitè de Bordeaux, EA 4577, USC 1366 INRA, ISVV, \\ 210 Chemin de Leysotte, 33882 Villenave d'Ornon CEDEX, France; aliciajouin@yahoo.fr (A.J.); \\ michael.jourdes@u-bordeaux.fr (M.J.); pierre-louis.teissedre@u-bordeaux.fr (P.-L.T.) \\ 3 Department of Agricultural, Food and Environmental Sciences, Università Politecnica delle Marche, \\ Via Brecce Bianche, 60100 Ancona, Italy; r.foligni@pm.univpm.it \\ 4 Faculty of Science and Technology, Free University of Bozen-Bolzano, Piazza Università 5, \\ 39100 Bolzano, Italy; emanuele.boselli@unibz.it \\ 5 Oenolab, NOITechPark Alto Adige/Südtirol, Via A. Volta 13B, 39100 Bolzano, Italy \\ * Correspondence: edoardo.longo@unibz.it; Tel.: +39-0471-017691
}

Academic Editors: María Ángeles Pozo-Bayón and Encarna Gómez-Plaza Received: 21 August 2020; Accepted: 16 September 2020; Published: 18 September 2020

\begin{abstract}
Different technical cork stoppers (blend of natural cork microgranules, one-piece natural cork, agglomerated natural cork, technical cork $1+1$ ) were compared to evaluate the effects on the phenolic, volatile profiles and dissolved oxygen in three red (Merlot, Lagrein red, St. Magdalener) and one rosé (Lagrein rosé) wines, which were stored in bottles for 12 months. Gallic acid, caffeic acid, $p$-coumaric acid, trans-resveratrol, glutahionyl caftaric acid and protocatechuic acid did not vary remarkably during the first three months, whereas at six months a net increase was reported, followed by a clear decrease at 12 months. The same trend was observed in Lagrein rosé, but only for gallic acid. The total anthocyanins content decreased during the storage period in the four wines. Isopentyl acetate, 1-hexanol, ethyl hexanoate, 2-phenylethyl alcohol, diethyl succinate, ethyl octanoate and ethyl decanoate were the main volatile compounds. The sum of alcohols decreased in all four of the wines. The esters decreased in Merlot; however, they increased in Lagrein rosé, Lagrein red and St. Magdalener during the storage. Univariate and multivariate statistics and a sensory discriminant triangle test displayed similar influences of the different stoppers on the phenolic and volatile compounds during the whole storage duration. The changes detected in the phenolic and volatile concentrations were presumably due to the non-oxygen-mediated reactions occurring during 12 months of storage in bottle.
\end{abstract}

Keywords: cork stoppers; red wine; rosé; chemometrics; bottle storage; sensory analysis; two-way ANOVA

\section{Introduction}

Between production and consumption, wine (especially red) spends a considerable part of its life cycle stored in the bottle. Differently from most food products, which are at their best quality level when fresh, wine needs an ageing period to reach its optimum quality. In the case of red wine, the quality is expected to evolve during the storage period, which can last even decades for some premium red wines [1]. Wine is a complex matrix that undergoes several changes during bottle storage involving chemical and organoleptic properties. Color, aroma, taste and mouthfeel are related to the quality of the 
product [2,3]. For example, phenolic compounds are responsible for several reactions in wine during bottle storage, such as changes in color, mouthfeel and oxidation level $[4,5]$. The aromatic characteristics of a young wine is primarily due to fruity and floral aromas derived from fermentation. During ageing, wine aroma tends to evolve as a result of the occurrence of numerous reactions. The excess of oxygen readily induces oxidative spoilage, which results in some off-odors such as cooked vegetable, woody, liquor and animal $[6,7]$ in the bottled wine. Other factors may also interact to affect the chemical profile, such as the light transmittance spectrum, due to the color of the bottle [8].

Moreover, oxygen can enter the bottle through the stopper at a rate dependent on the type of closure $[9,10]$. The parameter defining the amount of oxygen permeating a material is the oxygen transmission rate (OTR), which is often applied to assess the quality of wine closures [11]. Godden et al. [12] have confirmed the influence of the sealing system and the OTR on the evolution of wine during bottle storage. However, it may be misleading to consider the OTR as the only parameter related to the susceptibility of wine to oxidation during storage. In fact, aeration occurs in the different steps of the winemaking process starting from grape harvest and pressing [13] to the final package, and may dramatically affect the final wine quality. Determining the oxygen dissolved in wine before bottling has been the objective of extensive research [14]. While it is relatively easy to control the oxygen incorporation in tanks and vats during fermentation with a real-time approach $[15,16]$, the non-destructive monitoring of oxygen transfer during bottle storage for the comparison of different types of stoppers still remains a challenge [17]. Several aspects should be taken into consideration: Air can enter a bottle through the interface between the stopper and the bottleneck. The stopper itself can release oxygen after the compression at bottling, a phenomenon known as outgassing [18]. Hence, understanding the influence of the stopper may help to preserve the quality characteristics of wine against undesired alteration [10].

So far, few investigations have concerned the evolution of phenolic content after bottling in relation to type of stopper, storage time $[19,20]$ and oxygen content at bottling [21]. Other studies have outlined the relationships between the evolution of volatile profile and aroma in bottle-aged wines while considering oxygen content [22] and the use of different types of stoppers in Cabernet Sauvignon [23].

In this study, both the phenolic and volatile profiles of three red and one rosé wines from South Tyrol (Northern Italy) were monitored regularly over 12 months of bottle storage. The aim of this research was to investigate the influence of different types of stoppers on the evolution of wine quality, including a sensory evaluation. The outcomes of this study will provide new applied knowledge on stopper-wine interaction phenomena, as well as guidelines for the preservation of the quality attributes during the bottle storage of wines obtained from specific red varieties.

\section{Results}

\subsection{Evolution of Phenolic Compounds}

The profile of non-anthocyanin polyphenols is reported in Table 1.

Ten non-anthocyanin phenolic compounds were identified. Although each of the four wines had a different phenolic profile due to the different composition of the grape varieties used for winemaking, a common evolution trend was detected for six out of 10 compounds, namely, gallic acid, caffeic acid, $p$-coumaric acid, trans-resveratrol, glutathionyl caftaric acid (GRP) and protocatechuic acid. During the first three months of bottle storage (T1, T2, T3) their concentrations did not show notable variations. At six months (T4), a net increase was observed, followed by a clear decrease at 12 months (T5). This trend was detected in the three red wines; however, in Lagrein rosé, this evolution was registered only for gallic acid, but not for the other phenolic compounds. A decrease of the low molecular weight compounds such as caffeic acid, (+)-catechin, (-)-epicatechin and $p$-coumaric was observed when comparing the final concentrations (T5) with the initial ones (T1), as already reported in previous studies $[19,24]$. 
Table 1. Non-anthocyanin phenolic compounds $\left(\mathrm{mg} \mathrm{L}^{-1}\right)$ and significance of the type of stopper and storage time on their modifications.

\begin{tabular}{|c|c|c|c|c|c|c|c|c|c|c|c|c|c|c|c|c|c|c|c|c|c|c|c|c|c|c|}
\hline & \multicolumn{6}{|c|}{ Gallic Acid } & \multicolumn{5}{|c|}{ Protocatechuic Acid } & \multicolumn{5}{|c|}{ Caftaric Acid } & \multicolumn{5}{|c|}{ GRP } & \multicolumn{5}{|c|}{ (+)-Catechin } \\
\hline & Time & c & Blend & $F 1$ & $F 2$ & F3 & c & Blend & $F 1$ & $F 2$ & F3 & c & Blend & $F 1$ & $F 2$ & $F 3$ & c & Blend & $F 1$ & $F 2$ & F3 & c & Blend & $F 1$ & $F 2$ & $F 3$ \\
\hline \multirow{4}{*}{ Lagrein Red } & $\mathrm{T}_{\mathrm{T}}^{\mathrm{T}}$ & $16.2 \pm 0.5$ & $16.3 \pm 0.1$ & & & ns & $1.4 \pm 0$ & $1.3 \pm 0.1$ & \multirow{4}{*}{ ns } & \multirow{4}{*}{$1143 *$} & ns & $19.9 \pm 1.2$ & $18.8 \pm 0.7$ & \multirow{4}{*}{ ns } & \multirow{4}{*}{356.5 * } & ns & $1 \pm 0.1$ & $1 \pm 0.1$ & \multirow{4}{*}{ ns } & \multirow{4}{*}{$626.7 *$} & ns & $23.7 \pm 0.1$ & $24.2 \pm 2.5$ & \multirow{4}{*}{$14.1 *$} & \multirow{4}{*}{$81.7^{*}$} & ns \\
\hline & T3 & $\begin{array}{c}18 \pm 0 \\
18.7 \pm 1.4\end{array}$ & $\begin{array}{c}18 \pm 0.5 \\
18.4 \pm 0.1\end{array}$ & $\mathrm{~ns}$ & $1932 *$ & ns & $\begin{array}{l}1.2 \pm 0.1 \\
1.4 \pm 0\end{array}$ & $\begin{array}{c}0.9 \pm 0 \\
2.2 \pm 0.7\end{array}$ & & & $\begin{array}{l}18 \\
\text { ns }\end{array}$ & $\begin{array}{l}20.0 \pm 0.2 \\
22.1 \pm 0.1\end{array}$ & $\begin{array}{l}23.7 \pm 1.2 \\
20.6+0.8\end{array}$ & & & $\begin{array}{l}\text { nis } \\
\text { ns }\end{array}$ & $\begin{array}{l}1 \pm 0.1 \\
1+0\end{array}$ & $\begin{array}{l}0.8 \pm 0 \\
1+0.1\end{array}$ & & & $\begin{array}{l}\text { nis } \\
\text { ns }\end{array}$ & $\begin{array}{l}24.9 \pm 1.2 \\
23.9+0.3\end{array}$ & $\begin{array}{c}24.6 \pm 2.2 \\
18+0.4\end{array}$ & & & $\begin{array}{c}\text { ns } \\
*\end{array}$ \\
\hline & T4 & $47.6 \pm 0.7$ & $46.5 \pm 0.1$ & & & ns & $9.9 \pm 0.1$ & $10.3 \pm 0.3$ & & & ns & $41.5 \pm 3.5$ & $38.8 \pm 0$ & & & $\begin{array}{l}\text { ns } \\
\text { ns }\end{array}$ & $17.3 \pm 1.8$ & $\begin{array}{c}16.3 \pm 0.4\end{array}$ & & & $\begin{array}{l}\text { ns } \\
\text { ns }\end{array}$ & $20 \pm 0.2$ & $12.5 \pm 0.5$ & & & * \\
\hline & T5 & $21.7 \pm 0.2$ & $21.4 \pm 0.4$ & & & ns & $3.3 \pm 0.1$ & $3.5 \pm 0.1$ & & & ns & $47.5 \pm 0.1$ & $47.2 \pm 0$ & & & ns & $1.5 \pm 0.1$ & $1.5 \pm 0.1$ & & & ns & $15.7 \pm 0.2$ & $14.7 \pm 0.5$ & & & ns \\
\hline \multirow{4}{*}{$\begin{array}{l}\text { Lagrein } \\
\text { Rosè }\end{array}$} & $\begin{array}{ll}\text { T1 } \\
\end{array}$ & $3.8 \pm 0.1$ & $4.1 \pm 0.1$ & & & ns & $0.5 \pm 0$ & $0.5 \pm 0$ & \multirow{4}{*}{ ns } & \multirow{4}{*}{$27^{*}$} & ns & $3.8 \pm 0$ & $3.8 \pm 0.2$ & \multirow{4}{*}{ ns } & & ns & $1.4 \pm 0$ & $1.3 \pm 0.1$ & & & ns & $7.1 \pm 0.2$ & $7.4 \pm 0.6$ & & & ns \\
\hline & $\mathrm{T} 2$ & $3.7 \pm 0.2$ & $4 \pm 0.2$ & & & ns & $0.4 \pm 0$ & $0.4 \pm 0$ & & & ns & $4.2 \pm 0.2$ & $4.5 \pm 0.1$ & & & ns & $1.3 \pm 0.1$ & & & & ns & $5.4 \pm 0.4$ & & & & ns \\
\hline & $\begin{array}{l}\text { T3 } \\
\text { T4 }\end{array}$ & $\begin{array}{l}4.6 \pm 0.1 \\
6 \pm 0.1\end{array}$ & $\begin{array}{c}4.9 \pm 0 \\
59 \pm 0\end{array}$ & ns & $751^{*}$ & ns & $0.6 \pm 0.1$ & $\begin{array}{l}0.5 \pm 0 \\
0.5 \pm 0\end{array}$ & & & ns & $3.7 \pm 0.1$ & $3.8 \pm 0.1$ & & $786^{*}$ & ns & $1.2 \pm 0$ & $1.2 \pm 0$ & ns & $8570^{*}$ & ns & $5 \pm 1.1$ & $\begin{array}{l}5 \pm 0 \\
68\end{array}$ & ns & $29 *$ & ns \\
\hline & $\begin{array}{l}14 \\
\text { T5 }\end{array}$ & $\begin{array}{l}6 \pm 0.1 \\
1.6 \pm 0.1\end{array}$ & $\begin{array}{l}5.9 \pm 0.1 \\
1.6 \pm 0.1\end{array}$ & & & $\begin{array}{l}\text { ns } \\
\text { ns }\end{array}$ & $\begin{array}{l}0.6 \pm 0.1 \\
0.8 \pm 0.1\end{array}$ & $\begin{array}{l}0.5 \pm 0 \\
0.8 \pm 0.1\end{array}$ & & & $\begin{array}{l}\text { ns } \\
\text { ns }\end{array}$ & $\begin{array}{l}6.8 \pm 0 \\
7.1 \pm 0.1\end{array}$ & $\begin{array}{c}6.8 \pm 0 \\
7.1 \pm 0.1\end{array}$ & & & $\begin{array}{l}\text { ns } \\
\text { ns }\end{array}$ & $\begin{array}{l}8.2 \pm 0 \\
4.7 \pm 0\end{array}$ & $\begin{array}{l}8.2 \pm 0.11 \\
4.7 \pm 0\end{array}$ & & & $\begin{array}{l}\text { ns } \\
\text { ns }\end{array}$ & $\begin{array}{l}6.8 \pm 0 \\
4.5 \pm 0.1\end{array}$ & $\begin{array}{l}6.8 \pm 0 \\
4.2 \pm 0.1\end{array}$ & & & $\begin{array}{l}\text { ns } \\
\text { ns }\end{array}$ \\
\hline & T1 & $19.9 \pm 0.2$ & $21.1 \pm 0.7$ & & & ns & $1.7 \pm 0.1$ & $1.7 \pm 0.2$ & & & ns & $18.1 \pm 0.2$ & $17.5 \pm 1.1$ & & & ns & $1.5 \pm 0.3$ & $1.4 \pm 0.2$ & & & ns & $35 \pm 2$ & $37.8 \pm 2.4$ & & & ns \\
\hline & T2 & $24.1 \pm 0.6$ & $26 \pm 1$ & & & ns & n.d. & & & & ns & $21.4 \pm 0.5$ & $23.4 \pm 0.2$ & & & ns & & & & & ns & & & & & ns \\
\hline Merlot & $\begin{array}{l}\text { T3 } \\
\text { T4 }\end{array}$ & $\begin{array}{l}26.8 \pm 0.4 \\
599+0.5\end{array}$ & $\begin{array}{l}26.8 \pm 0.2 \\
593+0.2\end{array}$ & ns & $1526 *$ & ns & $\begin{array}{l}1.8 \pm 0.3 \\
48+0 .\end{array}$ & $\begin{array}{l}1.9 \pm 0.1 \\
48 \pm 01\end{array}$ & ns & $534^{*}$ & ns & $20.3 \pm 1.5$ & $20.2 \pm 0.4$ & ns & $292.4^{*}$ & ns & $\begin{array}{c}1.1 \pm 0 \\
\end{array}$ & $1.1 \pm 0$ & ns & $3263^{*}$ & ns & $37.7 \pm 0.7$ & $37.1 \pm 5$ & ns & $21.56^{*}$ & ns \\
\hline & $\begin{array}{l}14 \\
\text { T5 }\end{array}$ & $\begin{array}{l}5.990 \pm 0.3 \\
28.7 \pm 1.6\end{array}$ & $\begin{array}{l}59.3 \pm 0.2 \\
29.8 \pm 0.5\end{array}$ & & & $\begin{array}{l}\text { ns } \\
\text { ns }\end{array}$ & 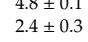 & $\begin{array}{l}4.8 \pm 0.1 \\
2.7 \pm 0.1\end{array}$ & & & $\begin{array}{l}\text { ns } \\
\text { ns }\end{array}$ & $\begin{array}{l}35.7 \pm 0.1 \\
42.5 \pm 2.1\end{array}$ & $\begin{array}{l}35.4 \pm 0.2 \\
44.2 \pm 2.3\end{array}$ & & & $\begin{array}{l}\text { ns } \\
\text { ns }\end{array}$ & $\begin{array}{l}12.7 \pm 0.3 \\
4.7 \pm 0.2\end{array}$ & $\begin{array}{l}12.8 \pm 0 \\
4.9 \pm 0.2\end{array}$ & & & $\begin{array}{l}\text { ns } \\
\text { ns }\end{array}$ & $\begin{array}{l}24.5 \pm 0.1 \\
24.2 \pm 0.8\end{array}$ & $\begin{array}{l}23.6 \pm 0.3 \\
24.5 \pm 0.1\end{array}$ & & & $\begin{array}{l}\text { ns } \\
\text { ns }\end{array}$ \\
\hline & T1 & $4.8 \pm 0.3$ & $4.7 \pm 0.1$ & & & ns & $3.3 \pm 0.2$ & $3.3 \pm 0.5$ & & & ns & $22.4 \pm 1.9$ & $20.3 \pm 1.2$ & & & ns & $1.6 \pm 0.2$ & $1.5 \pm 0$ & & & ns & $30.2 \pm 0.9$ & $30.7 \pm 1.1$ & & & ns \\
\hline & $\mathrm{T} 2$ & $5.4 \pm 1$ & $4.5 \pm 0.2$ & & & ns & $2.7 \pm 0.2$ & $1.8 \pm 0.4$ & & & ns & $23 \pm 1.9$ & & & & ns & & & & & ns & & & & & ns \\
\hline Magdalener & T3 & $\begin{array}{l}4.6 \pm 0.2 \\
152 \pm 0.2\end{array}$ & $\begin{array}{l}4.3 \pm 0.4 \\
142 \pm 0\end{array}$ & ns & $404^{*}$ & ns & $\begin{array}{r}2.4 \pm 0.3 \\
46+0.9\end{array}$ & $\begin{array}{l}2.1 \pm 0.2 \\
42+0.2\end{array}$ & ns & $21.9^{*}$ & ns & $21.4 \pm 0.3$ & $20.2 \pm 0.2$ & ns & $474^{*}$ & ns & $1.5 \pm 0.1$ & $1.4 \pm 0.3$ & ns & 2861 * & ns & $31.3 \pm 0.1$ & $28.6 \pm 1.4$ & ns & $56.4^{*}$ & ns \\
\hline & $\begin{array}{l}14 \\
\mathrm{~T} 5\end{array}$ & $\begin{array}{c}15.2 \pm 0.4 \\
6.2 \pm 0.1\end{array}$ & $\begin{array}{l}14.2 \pm 0 \\
5.9 \pm 0.6\end{array}$ & & & $\begin{array}{l}\text { ns } \\
\text { ns }\end{array}$ & 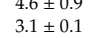 & $\begin{array}{l}4.2 \pm 0.1 \\
3.2 \pm 0.1\end{array}$ & & & $\begin{array}{l}\text { ns } \\
\text { ns }\end{array}$ & $\begin{array}{c}39.4 \pm 0.9 \\
46.9 \pm 1\end{array}$ & $\begin{array}{l}37.8 \pm 0.4 \\
47.1 \pm 0.6\end{array}$ & & & $\begin{array}{l}\text { ns } \\
\text { ns }\end{array}$ & $\begin{array}{c}22.2 \pm 0.8 \\
6.1 \pm 0.1\end{array}$ & $\begin{array}{l}21.1 \pm 0 \\
6 \pm 0.2\end{array}$ & & & ns & $\begin{array}{l}24.7 \pm 5 \\
22.1 \pm 0.8\end{array}$ & $\begin{array}{l}21.3 \pm 0.3 \\
21.6 \pm 0.2\end{array}$ & & & $\begin{array}{l}\text { ns } \\
\text { ns }\end{array}$ \\
\hline & & & Caffeic & & & & & Syringi & Acid & & & & $(-)-E_{1}$ & icatechi & & & & $P$-coumar & ic Acid & & & & Trans-Re & veratrol & & \\
\hline & Time & $\mathrm{c}$ & blend & $F 1$ & $F 2$ & F3 & c & blend & $F 1$ & $F 2$ & F3 & c & blend & $F 1$ & $F 2$ & F3 & c & blend & $F 1$ & $F 2$ & F3 & $\mathrm{c}$ & blend & $F 1$ & $F 2$ & $F 3$ \\
\hline & $\begin{array}{ll}\mathrm{T} 1 \\
\mathrm{~T} 2\end{array}$ & $3.7 \pm 0.1$ & $3.6 \pm 0$ & & & ns & $7.7 \pm 1$ & $8.2 \pm 0.4$ & & & ns & $26.2 \pm 1.2$ & $24.7 \pm 0.5$ & & & ns & $6.1 \pm 0.1$ & $5.7 \pm 0.1$ & & & ns & $3.4 \pm 1.4$ & $4 \pm 0$ & & & ns \\
\hline & $\mathrm{T} 2$ & $3.8 \pm 0$ & $4.6 \pm 0$ & & & ns & $6.9 \pm 0.1$ & $6.5 \pm 0.1$ & & & ns & $28.2 \pm 0.2$ & & & & ns & $5.3 \pm 0$ & & & & * & & $4.2 \pm 0.1$ & & & ns \\
\hline Lagrein Red & T3 & $4.1 \pm 0.6$ & $1.7 \pm 0.1$ & ns & $1132 *$ & ${ }^{*}$ & $6.1 \pm 0.4$ & $6.3 \pm 0.5$ & ns & $144^{*}$ & ns & $25.2 \pm 1.8$ & $20.5 \pm 6.3$ & ns & $80 *$ & ns & $6.1 \pm 0.2$ & $6.2 \pm 0.5$ & $8.2 *$ & 4297 * & ns & $3.4 \pm 0.5$ & $3.6 \pm 0$ & ns & $160.5^{*}$ & ns \\
\hline & $\begin{array}{l}\text { T4 } \\
\text { T5 }\end{array}$ & $\begin{array}{c}27.4 \pm 1.7 \\
2.1 \pm 0.1\end{array}$ & $\begin{array}{c}25.3 \pm 0.2 \\
2.1 \pm 0.4\end{array}$ & & & ns & $\begin{array}{c}3.9 \pm 0 \\
1.9 \pm 0.3\end{array}$ & $\begin{array}{c}4.2 \pm 0.1 \\
1.8 \pm 0\end{array}$ & & & $\begin{array}{l}\text { ns } \\
\text { ns }\end{array}$ & $\begin{array}{c}5.3 \pm 0 \\
1.7 \pm 0.1\end{array}$ & $\begin{array}{l}4.7 \pm 0.1 \\
10.2 \pm 0.4\end{array}$ & & & ns & $\begin{array}{l}24.7 \pm 0.7 \\
3.7 \pm 0\end{array}$ & $\begin{array}{l}25.6 \pm 0 \\
3.6 \pm 0.1\end{array}$ & & & $\begin{array}{l}\text { ns } \\
\text { ns }\end{array}$ & $\begin{array}{l}12.4 \pm 0.8 \\
8.6 \pm 0.2\end{array}$ & $\begin{array}{l}11.8 \pm 0.4 \\
8.7 \pm 0.2\end{array}$ & & & $\begin{array}{l}\text { ns } \\
\text { ns }\end{array}$ \\
\hline & $\mathrm{T} 1$ & & & & & ns & $1.5 \pm 0$ & $1.5 \pm 0.4$ & & & ns & $2.2 \pm 0.3$ & & & & ns & $2.8 \pm 0.1$ & & & & ns & $2.4 \pm 0.1$ & & & & ns \\
\hline & T2 & & & & & ns & $1.3 \pm 0.2$ & $1.6 \pm 0.4$ & & & ns & $2.1 \pm 0.6$ & $2.8 \pm 0.3$ & & & ns & $3.5 \pm 0.1$ & $3.9 \pm 0.2$ & & & * & & & & & ns \\
\hline $\begin{array}{l}\text { Lagrenn } \\
\text { Rosè }\end{array}$ & T3 & $5.5 \pm 1.7$ & $4.1 \pm 0.9$ & ns & 41 * & ns & $1.3 \pm 0.1$ & $1.2 \pm 0.2$ & ns & $24 *$ & ns & $2.8 \pm 0.9$ & $1.5 \pm 0$ & $5.6^{*}$ & $15 *$ & ns & $2.9 \pm 0$ & $2.9 \pm 0$ & $6.8^{*}$ & $1328^{*}$ & ns & & $2.5 \pm$ & ns & 1899 * & ns \\
\hline & $\begin{array}{l}\text { T4 } \\
\text { T5 }\end{array}$ & $\begin{array}{c}2.4 \pm 0.1 \\
0 \pm 0\end{array}$ & $\begin{array}{c}2.4 \pm 0 \\
0 \pm 0\end{array}$ & & & $\begin{array}{l}\text { ns } \\
\text { ns }\end{array}$ & $\begin{array}{l}0.2 \pm 0 \\
0.9 \pm 0\end{array}$ & $\begin{array}{l}0.2 \pm 0 \\
0.9 \pm 0\end{array}$ & & & $\begin{array}{l}\text { ns } \\
\text { ns }\end{array}$ & $\begin{array}{c}1.9 \pm 0 \\
3.3 \pm 0.1\end{array}$ & $\begin{array}{c}1.9 \pm 0 \\
3.7 \pm 0.6\end{array}$ & & & $\begin{array}{l}\text { ns } \\
\text { ns }\end{array}$ & $\begin{array}{l}1.9 \pm 0 \\
0.1 \pm 0\end{array}$ & $\begin{array}{l}1.8 \pm 0 \\
0.1 \pm 0\end{array}$ & & & $\begin{array}{l}\text { ns } \\
\text { ns }\end{array}$ & $\begin{array}{c}0.4 \pm 0 \\
0.3 \pm 0.1\end{array}$ & $\begin{array}{l}0.5 \pm 0 \\
0.2 \pm 0\end{array}$ & & & $\begin{array}{l}\text { ns } \\
\text { ns }\end{array}$ \\
\hline & $\mathrm{T} 1$ & $1.9 \pm 0.1$ & $2.3 \pm 0.1$ & & & ns & $4.6 \pm 1.1$ & $3.9 \pm 1.4$ & & & ns & $41.7 \pm 0.2$ & $42.7 \pm 6.5$ & & & ns & $7.9 \pm 0$ & $7.6 \pm 1$ & & & ns & $2.9 \pm 0.7$ & $3.5 \pm 0.1$ & & & ns \\
\hline & T2 & & & & & ns & & & & & ns & & & & & & & & & & ns & & & & & ns \\
\hline Merlot & T3 & $1.7 \pm 0$ & $1.5 \pm 0.1$ & ns & 3435 * & ns & $3.3 \pm 0.4$ & $3.2 \pm 0.3$ & ns & $30.3^{*}$ & ns & $41.2 \pm 1.2$ & $39.7 \pm 5.1$ & ns & $274.1^{*}$ & ns & $7.6 \pm 0.4$ & $7.5 \pm 1.5$ & ns & $282.7^{*}$ & ns & $3.6 \pm$ & $3.5 \pm 0.1$ & ns & $143.3^{*}$ & ns \\
\hline & $\begin{array}{l}\text { T4 } \\
\text { T5 }\end{array}$ & $\begin{array}{l}16 \pm 0.1 \\
0.7 \pm 0.2\end{array}$ & $\begin{array}{l}16.1 \pm 0.5 \\
0.6 \pm 0.2\end{array}$ & & & $\begin{array}{l}\text { ns } \\
\text { ns }\end{array}$ & $\begin{array}{l}2.3 \pm 0.1 \\
0.4 \pm 0.1\end{array}$ & $\begin{array}{l}2.3 \pm 0.1 \\
0.5 \pm 0.1\end{array}$ & & & $\begin{array}{l}\text { ns } \\
\text { ns }\end{array}$ & $\begin{array}{l}10.5 \pm 0 \\
16.7 \pm 1\end{array}$ & $\begin{array}{l}10.1 \pm 0.3 \\
17 \pm 0.4\end{array}$ & & & $\begin{array}{l}\text { ns } \\
\text { ns }\end{array}$ & $\begin{array}{l}19.4 \pm 0.1 \\
1.5 \pm 0.1\end{array}$ & $\begin{array}{l}19.4 \pm 0.2 \\
1.6 \pm 0\end{array}$ & & & $\begin{array}{l}\text { ns } \\
\text { ns }\end{array}$ & $\begin{array}{l}16 \pm 0.1 \\
8.1 \pm 2.3\end{array}$ & $\begin{array}{l}15.4 \pm 0.8 \\
9.5 \pm 0.4\end{array}$ & & & $\begin{array}{l}\text { ns } \\
\text { ns }\end{array}$ \\
\hline & & $1.2 \pm 0$ & $\begin{array}{c}0.0 \pm 0.2 \\
1.2 \pm 0.1\end{array}$ & & & ns & $5.5 \pm 0.4$ & $5.0 \pm 0.19$ & & & & $22.7 \pm 1.1$ & $21.1 \pm 0.6$ & & & ns & $3.5 \pm 0$ & $3.7 \pm 0.2$ & & & ns & $\frac{0.1 \pm z \pm 0}{2.7 \pm 0}$ & $\frac{1.5 \pm 0.7}{2.7 \pm 0}$ & & & ns \\
\hline & T2 & & & & & ns & & & & & ns & & & & & & & & & & ns & & & & & ns \\
\hline Magdalener & $\mathrm{T} 3$ & $1 \pm 0$ & $1 \pm 0.1$ & ns & 517 * & ns & $3.3 \pm$ & $3.2 \pm 0.1$ & ns & 319 * & ns & $18.3 \pm 0.6$ & $16.5 \pm 0.2$ & ns & 101 * & ns & & $3.8 \pm 0$ & ns & 705 * & ns & $2.6 \pm 0$ & $2.7 \pm 0$ & ns & $22.8^{*}$ & ns \\
\hline & $\begin{array}{l}\text { T4 } \\
\text { T5 }\end{array}$ & $\begin{array}{c}16.6 \pm 1.8 \\
0 \pm 0\end{array}$ & $\begin{array}{c}17.6 \pm 0.1 \\
0 \pm 0\end{array}$ & & & $\begin{array}{l}\text { ns } \\
\text { ns }\end{array}$ & $\begin{array}{l}0.8 \pm 0.1 \\
0.3 \pm 0\end{array}$ & $\begin{array}{l}0.9 \pm 0 \\
0.3 \pm 0\end{array}$ & & & $\begin{array}{l}\text { ns } \\
\text { ns }\end{array}$ & $\begin{array}{c}7.8 \pm 2.8 \\
12.1 \pm 0.2\end{array}$ & $\begin{array}{c}9.3 \pm 0 \\
11.4 \pm 0.6\end{array}$ & & & $\begin{array}{l}\text { ns } \\
\text { ns }\end{array}$ & $\begin{array}{l}15.4 \pm 1 \\
3.2 \pm 0\end{array}$ & $\begin{array}{l}16.2 \pm 0.2 \\
3.2 \pm 0.1\end{array}$ & & & $\begin{array}{l}\text { ns } \\
\text { ns }\end{array}$ & 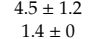 & $\begin{array}{l}3.5 \pm 0.1 \\
1.3 \pm 0.4\end{array}$ & & & $\begin{array}{l}\text { ns } \\
\text { ns }\end{array}$ \\
\hline
\end{tabular}

Legend: F1, F (interaction); F2, F (storage period); F3, F (stopper); blend, blend stopper; c, conventional stopper, as reported in Table 6. T1: samples at bottling; T2: after one month of storage at cellar temperature; T3: after three months of storage at cellar temperature; T4: after six months of storage at cellar temperature; T5: after 12 months of storage at cellar temperature. ns: not significant difference; *: significant difference $(p<0.05)$; n.d.: not detected. 
The anthocyanins were derivatives of delphinidin, cyanidin, petunidin, peonidin and malvidin, which are the typical anthocyanins present in wines obtained from Vitis vinifera $\mathrm{L}$. red grape varieties. Anthocyanins were grouped in three families according to the esterification groups: glucosides, acetyl-glucosides and coumaroyl-glucosides. Their concentrations are reported in Table 2.

The glucosides-anthocyanins included delphinidin-3-O-glucoside, cyanidin-3-O-glucoside, petunidin-3-O-glucoside, peonidin-3-O-glucoside and malvidin-3-O-glucoside. Acetyl-glucosides included delphinidin-3-O-acetylglucoside, petunidin-3-O-acetylglucoside, peonidin-3-O-acetylglucoside and malvidin-3-O-acetylglucoside. Coumaroyl-glucosides grouped petunidin-3-O-coumaroylglucoside, peonidin-3-O-coumaroylglucoside and malvidin-3-O-coumaroylglucoside. At bottling time T1, the Lagrein red wine had the highest concentration of anthocyanins compared to Merlot and St. Magdalener. The total anthocyanins content of Lagrein was almost double that of Merlot, whereas non-acylated anthocyanins in Lagrein were about $265 \mathrm{mg} \mathrm{L}^{-1}$ compared to about $160 \mathrm{mg} \mathrm{L}^{-1}$ for Merlot and about $142 \mathrm{mg} \mathrm{L}^{-1}$ in St. Magdalener. Acetylated and coumaroylated anthocyanins were also present in higher concentrations in Lagrein red (86 mg L $\mathrm{m}^{-1}$ and $27 \mathrm{mg} \mathrm{L}^{-1}$, respectively), followed by Merlot (48 and $19 \mathrm{mg} \mathrm{L}^{-1}$, respectively) and St. Magdalener (29 and $13 \mathrm{mg} \mathrm{L}^{-1}$, respectively). Rosé wine produced from Lagrein had a predictably much lower concentration of anthocyanins (non-acylated, about $28 \mathrm{mg} \mathrm{L}^{-1}$; acetylated, about $14 \mathrm{mg} \mathrm{L}^{-1}$; coumaroylated about $7 \mathrm{mg} \mathrm{L}^{-1}$ ) compared to the three red wines, due to the shorter maceration time. Nonetheless, in all four wines the sum of the three classes and thus the total amount of identified anthocyanins showed a clear decrease over the storage period. The reduction of the phenolic content during the bottle storage is generally ascribed to polymerization, oxidation and complexation reactions [25-27]. In this case the dissolved oxygen present in the four wines (Table 3) was low already just after bottling (0.15-1.7 $\mathrm{mg} \mathrm{L}^{-1}$ in red and 1.4-3.1 $\mathrm{mg} \mathrm{L}^{-1}$ in rosé wine) and varied slightly during 12 months of storage. 
Table 2. Anthocyanin concentrations $\left(\mathrm{mg} \mathrm{L}^{-1}\right)$ and significance of the type of stopper and storage time on their modifications. T1: samples at bottling; T2: after one month of storage at cellar temperature; T3: after three months of storage at cellar temperature; T4: after six months of storage at cellar temperature; T5: after 12 months of storage at cellar temperature.

\begin{tabular}{|c|c|c|c|c|c|c|c|c|c|c|c|c|c|c|c|c|}
\hline & \multicolumn{6}{|c|}{ Glucoside } & \multicolumn{5}{|c|}{ Acetyl-Glucoside } & \multicolumn{5}{|c|}{ Cumaroyl-Glucoside } \\
\hline & Time & c & Blend & $F 1$ & $F 2$ & F3 & c & Blend & $F 1$ & $F 2$ & F3 & c & Blend & $F 1$ & F2 & $F 3$ \\
\hline \multirow{5}{*}{ Lagrein red } & T1 & $270.3 \pm 6.2$ & $266.2 \pm 0.4$ & \multirow{5}{*}{ ns } & \multirow{5}{*}{1481 * } & ns & $87 \pm 0.9$ & $85.7 \pm 0.1$ & \multirow{5}{*}{ ns } & \multirow{5}{*}{$1694^{*}$} & ns & $27.2 \pm 0.6$ & $27.6 \pm 0.2$ & \multirow{5}{*}{ ns } & \multirow{5}{*}{$1130 *$} & $\mathrm{~ns}$ \\
\hline & $\mathrm{T} 2$ & $253.3 \pm 4$ & $249.6 \pm 3.3$ & & & ns & $80.5 \pm 0.6$ & $79 \pm 1.9$ & & & ns & $26.1 \pm 0.3$ & $25.3 \pm 0.5$ & & & $\mathrm{~ns}$ \\
\hline & $\mathrm{T} 3$ & $206.4 \pm 0$ & $193.1 \pm 3.4$ & & & $*$ & $61.4 \pm 0$ & $58.9 \pm 0.7$ & & & ns & $20.7 \pm 0.1$ & $19.6 \pm 0.4$ & & & $\mathrm{~ns}$ \\
\hline & $\mathrm{T} 4$ & $206 \pm 0.4$ & $198 \pm 5.6$ & & & ns & $69.8 \pm 1$ & $64.3 \pm 2.7$ & & & $*$ & $21.1 \pm 0$ & $20.3 \pm 0.8$ & & & $\mathrm{~ns}$ \\
\hline & $\mathrm{T} 5$ & $83.3 \pm 5$ & $80 \pm 1.2$ & & & ns & $17.1 \pm 1.3$ & $17.2 \pm 0.4$ & & & ns & $9.8 \pm 0.2$ & $10 \pm 0.3$ & & & ns \\
\hline \multirow{5}{*}{ Lagrein rosè } & T1 & $28.2 \pm 0.2$ & $28.1 \pm 0.2$ & \multirow{5}{*}{ ns } & \multirow{5}{*}{34170 * } & ns & $14.2 \pm 0.1$ & $14.3 \pm 0$ & \multirow{5}{*}{ ns } & \multirow{5}{*}{$20423 *$} & ns & $7.4 \pm 0$ & $7.3 \pm 0.1$ & \multirow{5}{*}{ ns } & \multirow{5}{*}{10927 * } & $\mathrm{ns}$ \\
\hline & $\mathrm{T} 2$ & $27.8 \pm 0$ & $27.8 \pm 0.2$ & & & ns & $14 \pm 0.2$ & $13.9 \pm 0.1$ & & & ns & $3.9 \pm 0.1$ & $4 \pm 0.1$ & & & $\mathrm{~ns}$ \\
\hline & T3 & $25.7 \pm 0$ & $25.3 \pm 0$ & & & ns & $13 \pm 0.1$ & $13 \pm 0$ & & & ns & $3.8 \pm 0$ & $3.8 \pm 0$ & & & $\mathrm{~ns}$ \\
\hline & $\mathrm{T} 4$ & $12.8 \pm 0$ & $12.6 \pm 0.3$ & & & ns & $4.1 \pm 0.1$ & $4 \pm 0.1$ & & & ns & $0.8 \pm 0$ & $0.7 \pm 0.1$ & & & $\mathrm{~ns}$ \\
\hline & T5 & $5.8 \pm 0$ & $5.7 \pm 0$ & & & ns & $1 \pm 0$ & $1 \pm 0$ & & & ns & $0.4 \pm 0$ & $0.4 \pm 0$ & & & $\mathrm{~ns}$ \\
\hline \multirow{5}{*}{ Merlot } & $\mathrm{T} 1$ & $163.8 \pm 1.4$ & $159.7 \pm 2.6$ & \multirow{5}{*}{ ns } & \multirow{5}{*}{$3439 *$} & ns & $46 \pm 0.5$ & $51.6 \pm 0.9$ & \multirow{5}{*}{$15.5^{*}$} & \multirow{5}{*}{$1941 *$} & * & $19.2 \pm 0.3$ & $18.9 \pm 0.1$ & \multirow{5}{*}{ ns } & \multirow{5}{*}{$979 *$} & $\mathrm{~ns}$ \\
\hline & $\mathrm{T} 2$ & $152.7 \pm 0.7$ & $149.9 \pm 0$ & & & ns & $42.8 \pm 0.3$ & $47.6 \pm 0.5$ & & & * & $18.6 \pm 0.3$ & $18.1 \pm 0.1$ & & & $\mathrm{~ns}$ \\
\hline & T3 & $123.1 \pm 0.2$ & $121.5 \pm 0.4$ & & & ns & $35.7 \pm 0.6$ & $38.1 \pm 0.9$ & & & * & $15.6 \pm 0.3$ & $15.3 \pm 0.1$ & & & $\mathrm{~ns}$ \\
\hline & $\mathrm{T} 4$ & $117.1 \pm 0.7$ & $114.4 \pm 3.9$ & & & ns & $30.4 \pm 0.2$ & $30.3 \pm 1$ & & & ns & $13.5 \pm 0.1$ & $13.1 \pm 0.8$ & & & $\mathrm{~ns}$ \\
\hline & T5 & $48.4 \pm 1.1$ & $47.6 \pm 0.4$ & & & ns & $9.9 \pm 0.1$ & $9.6 \pm 0.4$ & & & ns & $7.2 \pm 0.1$ & $6.8 \pm 0$ & & & $\mathrm{~ns}$ \\
\hline \multirow{5}{*}{ St Magdalener } & T1 & $142.5 \pm 1.7$ & $142.7 \pm 0.4$ & \multirow{5}{*}{$4.5^{*}$} & \multirow{5}{*}{$4767^{*}$} & ns & $29.6 \pm 0.1$ & $28.9 \pm 0.1$ & \multirow{5}{*}{$5.6^{*}$} & \multirow{5}{*}{$2971 *$} & ns & $13.5 \pm 0.2$ & $13.4 \pm 0$ & \multirow{5}{*}{ ns } & & $\mathrm{ns}$ \\
\hline & $\mathrm{T} 2$ & $138.6 \pm 0$ & $137.2 \pm 0.1$ & & & ns & $28.9 \pm 0.1$ & $28.6 \pm 0.1$ & & & ns & $13.4 \pm 0.3$ & $13.6 \pm 0.2$ & & & $\mathrm{~ns}$ \\
\hline & $\mathrm{T} 3$ & $118.2 \pm 1.1$ & $116.2 \pm 1.2$ & & & ns & $24.6 \pm 0.1$ & $24.5 \pm 0.4$ & & & ns & $12.1 \pm 0.1$ & $12 \pm 0.1$ & & $1867^{*}$ & $\mathrm{~ns}$ \\
\hline & $\mathrm{T} 4$ & $113 \pm 2.5$ & $103.1 \pm 2.9$ & & & $*$ & $16.2 \pm 0.5$ & $13.9 \pm 0.7$ & & & * & $10.6 \pm 0.1$ & $9.8 \pm 0.7$ & & & $\mathrm{~ns}$ \\
\hline & T5 & $47.6 \pm 0.3$ & $43.1 \pm 3.9$ & & & ns & $5.2 \pm 0$ & $4.6 \pm 0.4$ & & & ns & $0.9 \pm 0$ & $1 \pm 0.1$ & & & $\mathrm{~ns}$ \\
\hline
\end{tabular}

Legend: F1, F (interaction); F2, F (storage period); F3, F (stopper); blend, blend stopper; c, conventional stopper, as reported in Table 6. Anthocyanin glucosides included delphinidin-3-O-glucoside, cyanidin-3-O-glucoside, petunidin-3-O-glucoside, peonidin-3-O-glucoside and malvidin-3-O-glucoside. Acetyl-glucosides included delphinidin-3-Oacetylglucoside, petunidin-3-O-acetylglucoside, peonidin-3-O-acetylglucoside, malvidin-3-O-acetylglucoside. Coumaroyl-glucosides included petunidin-3-O-coumaroylglucoside, peonidin-3-O-coumaroylglucoside and malvidin-3-O-coumaroylglucoside. ns: not significant difference; *: significant difference $(p<0.05)$. 
Table 3. Dissolved oxygen $\left(\mathrm{mg} \mathrm{L}^{-1}\right)$.

\begin{tabular}{|c|c|c|c|c|}
\hline & Time & Blend & c & Significant Difference (95\% Confidence) \\
\hline \multirow{5}{*}{ Lagrein Red } & T1 & $0.40 \pm 0.00$ & $0.25 \pm 0.07$ & \multirow{5}{*}{ * } \\
\hline & $\mathrm{T} 2$ & $0.30 \pm 0.00$ & $0.20 \pm 0.00$ & \\
\hline & T3 & $0.20 \pm 0.00$ & $0.25 \pm 0.07$ & \\
\hline & $\mathrm{T} 4$ & $0.20 \pm 0.00$ & $0.20 \pm 0.14$ & \\
\hline & T5 & $0.45 \pm 0.07$ & $0.50 \pm 0.00$ & \\
\hline \multirow{5}{*}{ Lagrein Rosé } & $\mathrm{T} 1$ & $3.10 \pm 0.00$ & $1.40 \pm 0.00$ & * \\
\hline & $\mathrm{T} 2$ & $3.05 \pm 0.07$ & $2.20 \pm 0.14$ & * \\
\hline & T3 & $3.65 \pm 0.07$ & $2.45 \pm 0.07$ & * \\
\hline & $\mathrm{T} 4$ & $2.65 \pm 0.07$ & $1.90 \pm 0.00$ & \multirow[t]{2}{*}{ * } \\
\hline & T5 & $2.75 \pm 0.07$ & $2.90 \pm 0.00$ & \\
\hline \multirow{5}{*}{ Merlot } & $\mathrm{T} 1$ & $1.70 \pm 0.14$ & $1.3 \pm 0.28$ & \multirow{5}{*}{ * } \\
\hline & $\mathrm{T} 2$ & $2.35 \pm 0.21$ & $1.80 \pm 0.00$ & \\
\hline & T3 & $2.75 \pm 0.07$ & $2.15 \pm 0.07$ & \\
\hline & $\mathrm{T} 4$ & $1.25 \pm 0.07$ & $1.10 \pm 0.00$ & \\
\hline & $\mathrm{T} 5$ & $2.35 \pm 0.07$ & $2.55 \pm 0.07$ & \\
\hline \multirow{5}{*}{ St. Magdalener } & $\mathrm{T} 1$ & $0.35 \pm 0.07$ & $0.15 \pm 0.07$ & \multirow{5}{*}{$\begin{array}{l}* \\
*\end{array}$} \\
\hline & $\mathrm{T} 2$ & $0.30 \pm 0.00$ & $0.10 \pm 0.00$ & \\
\hline & $\mathrm{T} 3$ & $0.40 \pm 0.00$ & $0.20 \pm 0.00$ & \\
\hline & $\mathrm{T} 4$ & $0.10 \pm 0.00$ & $0.10 \pm 0.00$ & \\
\hline & T5 & $0.50 \pm 0.14$ & $0.45 \pm 0.07$ & \\
\hline
\end{tabular}

Legend: Blend, blend stopper; c, conventional stopper, as reported in Table $6 .{ }^{*}$ Significance level $(p<0.05)$ of difference between stoppers.

\subsection{Effect of the Type of Stopper and Storage Time on the Phenolic Profile}

Two-way ANOVA was performed to assess the influence of the type of stopper and the bottle storage time on the phenolic composition of the four wines. The results showed that the storage time (F storage time) significantly influenced the phenolic concentration (Tables 1 and 2). Notably, GRP and anthocyanin glucosides, acetyl-glucosides and coumaroyl-glucosides in Lagrein rosé $(\mathrm{F}=8570$; 34,170; 20,423 and 10,927, respectively); caffeic acid, GRP and glucoside in Merlot ( $\mathrm{F}=3435 ; 3263$ and 3435, respectively); GRP, glucosides and acetyl-glucosides in St. Magdalener ( $\mathrm{F}=2861 ; 4767$ and 2971, respectively); and $p$-coumaric acid in Lagrein $(\mathrm{F}=4297)$ were strongly affected by the storage period. On the other hand, the influence of the type of stopper at each sampling time (F stopper) a significantly affected the phenolic compounds only in a few cases.

Compared to the bottles closed with conventional stoppers, Lagrein red wine closed with the 'blend' stopper showed significantly lower concentrations of anthocyanin glucosides at three months (T3), acetyl glucosides at six months (T4), (+)-catechin and caffeic acid at three and six months and $p$-coumaric acid at one month of storage (T2). Merlot wines reported significant differences for anthocyanin acetyl-glucosides at bottling (T1), at one month (T2) and at three months (T3), but in this case higher concentrations were detected in the bottles closed with the 'blend' stoppers compared to the conventional stoppers. All these differences can be attributable to an imperfect homogeneity of the Merlot wine in the bottling line (for each sampling point, the content of different bottles were analyzed).

The Lagrein rosé wine showed a higher abundance of $p$-coumaric acid at T2 in the wine sample closed with the 'blend' stopper. St. Magdalener wines differed for the lower concentrations of GRP, anthocyanin glucosides and acetyl-glucosides after six months storage (T4) in bottles closed with the 'blend' stoppers.

To summarize, a common temporal trend of one or more phenolic compounds related to the type of stopper could not be evidenced in the four wines. The statistical differences highlighted between two types of stoppers were quite unpredictable and seemed to be due to the natural variability of the products. 
To better understand the influence of storage time and type of stopper on the phenolic profile in relation to dissolved oxygen, PCA was performed with all the phenolic compounds and the dissolved oxygen values obtained at each step of analysis. Rosé wines were excluded from the PCA because their content of phenolic compounds was lower than the red wines. The PCA plot showing the loading of variables and the scores of the samples in the bi-dimensional space is reported in Figure 1.

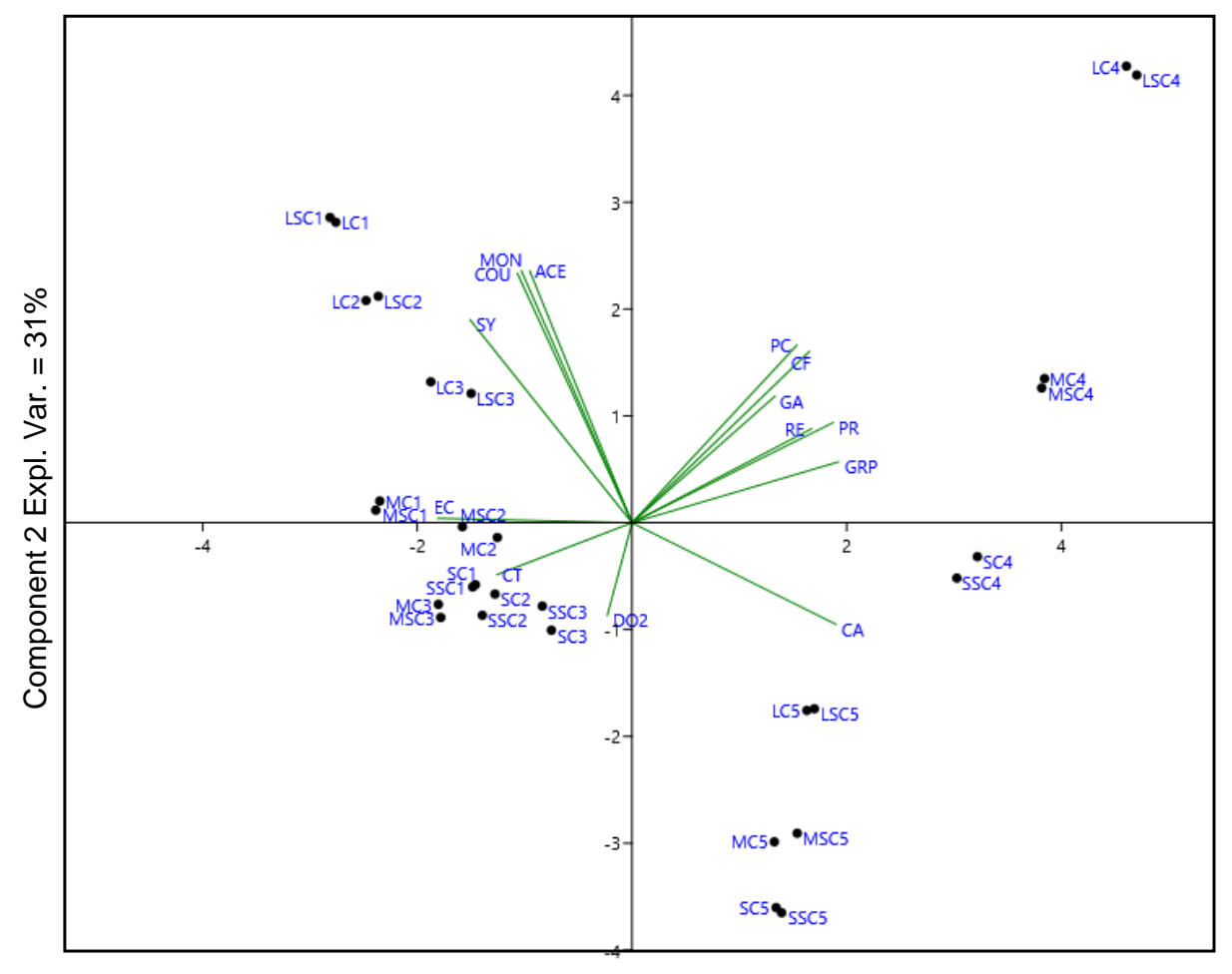

Component 1 Expl. Var. $=42 \%$

Figure 1. PCA bi-plot (\% explained total variance: PC-1, 42\%; PC-2, 31\%) of the three red wines closed with different stoppers considering the phenolic profiles and the dissolved oxygen $\left(\mathrm{DO}_{2}\right)$ during 12 months of bottle storage. Samples: SC and SSC, St. Magdalener closed with conventional stopper or 'blend' stopper, respectively. LC, LSC, Lagrein with conventional or 'blend' stopper, respectively; MC, MSC, Merlot. Storage in bottle: 1, wine just after bottling; 2,3,4,5, wine analyzed one, three, six and 12 months after bottling, respectively. Phenolic compounds: MON, non-acylated anthocyanins; ACE, acetylated anthocyanins; COU, coumaroylated anthocyanins; GA, gallic acid; PR, protocatechuic acid; GRP, glutathionyl caftaric acid; CA, caftaric acid; CF, caffeic acid; CT, catechin; EC, epicatechin; SY, syringic acid; PC, $p$-coumaric acid; RE, resveratrol.

The first two principal components made up 73\% of the model (PC-1 42\%, PC-2 31\%) when taken together. Samples collected at bottling time (T1), after one month (T2) and after three months (T3) were grouped on the negative side of the PC-1 axis, whereas the wines stored for six months (T4) and 12 months (T5) were placed on the positive side of the PC-1 axis. Considering the loadings, the three classes of phenolic anthocyanins (glucosides, acetyl-glucosides and coumaroyl-glucosides) and non-anthocyanin phenolic compounds, such as syringic acid, showed a positive correlation with Lagrein red samples collected at bottling time (T1), three months (T2) and at six months (T3). On the other hand, catechin and epicatechin showed a good correlation with Santa Madgalener and Merlot samples analyzed at T1, T2 and T3. Gallic acid, protocatechuic acid, GRP, caffeic acid, $p$-coumaric and trans-resveratrol were positively correlated with the Merlot and Lagrein samples collected after six months (T4). Caftaric acid characterized all the wines stored for 12 months (T5), as well as the St. Magdalener wines sampled at six months storage (T4).

The dissolved oxygen was not strongly correlated with any specific sample. 
This PCA model successfully scattered the samples depending on the storage period, whereas the bottles closed with similar stoppers were not clearly separated in any case. The multivariate approach confirmed the ANOVA results, remarking the dominant influence of the storage time over the type of stopper.

\subsection{Evolution of Volatile Compounds during the Storage in Bottle}

A total number of 26 volatile compounds were identified in all the wines (Table 4).

Table 4. List of volatile compounds (LRI, linear retention index).

\begin{tabular}{|c|c|c|}
\hline No. & Esters & LRI [Ref.] \\
\hline 2 & Ethyl butanoate & $803[28]$ \\
\hline 3 & 2-methylbutanoic acid, ethyl ester & $846[28]$ \\
\hline 4 & 3-methylbutanoic acid, ethyl ester & 859 [29] \\
\hline 6 & Isopentyl acetate & $876[30]$ \\
\hline 7 & 4-Ethylbenzoic acid, 2-butylester & - \\
\hline 10 & Ethyl hexanoate & $999[30]$ \\
\hline 11 & Hexyl acetate & $1011[30]$ \\
\hline 14 & 4-Methylbenzaldehyde & 1076 [31] \\
\hline 16 & 4-Ethylbenzaldehyde & $1163[32]$ \\
\hline 18 & Diethyl succinate & 1179 [33] \\
\hline 20 & Methyl salicylate & $1192[30]$ \\
\hline 21 & Ethyl octanoate & $1194[34]$ \\
\hline 22 & Benzenacetic acid ethyl ester & $1243[30]$ \\
\hline 23 & 2-Phenylethylacetate & $1255[30]$ \\
\hline 24 & Ethyl decanoate & 1392 [30] \\
\hline 25 & Ethyl dodecanoate & $1554[30]$ \\
\hline 26 & Ethyl hexadecanoate & $1992[35]$ \\
\hline No. & Alcohols & LRI [Ref.] \\
\hline 5 & 1-Hexanol & $865[30]$ \\
\hline 8 & 1-Heptanol & 969 [30] \\
\hline 9 & 1-Octen-3ol & $980[28]$ \\
\hline 13 & 2-Ethyl hexanol & $1028[36]$ \\
\hline 15 & Octanol & $1070[30]$ \\
\hline 17 & 2-Phenylethyl alcohol & $1112[28]$ \\
\hline No. & Acids & \\
\hline 1 & Acetic acid & $599[28]$ \\
\hline 19 & Octanoic acid & $1180[37]$ \\
\hline No. & Terpens & \\
\hline 12 & Limonene & $1020[30]$ \\
\hline
\end{tabular}

The main goal of the SPME-GC/MS analysis was not to obtain the absolute concentrations of the volatile compounds present in the wine headspace, but to study the relationships between their relative concentrations (profiles) and the technological variables (wine type/stopper type/storage time) with a multivariate statistical approach.

The abundances of the volatile compounds (averages and standard deviations of two replicate bottles) were expressed as relative percentage (internal area) considering all the volatile compounds, as reported in Supplementary Materials (tables of volatile compounds' average peak areas in the studied wines).

The most represented compounds were short- and medium-chain esters, which included 17 compounds, followed by higher alcohols, short- and medium-chain organic acids and terpenes. During the bottle storage, more than $80 \%$ of the total abundance was represented by seven compounds: isopentyl acetate, 1-hexanol, ethyl hexanoate, 2-phenylethyl alcohol, diethyl succinate, ethyl octanoate 
and ethyl decanoate. Over 12 months, the modification of the volatile profile was primarily due to the evolution of these compounds. Ethyl octanoate and ethyl decanoate showed a decreasing trend in the early period of bottle storage (T2-T4), followed by an increase until the 12th month (T5) in red wines. Isopentyl acetate increased after one month (T2) of bottle storage in the three red wines and reached its maximum abundance at three months (T3), probably as a consequence of acid-catalyzed reactions involving fatty acid esters and resulting in the production of acetate esters $[38,39]$.

The sum of higher alcohols decreased in all four of the wines. This reduction was detected in previous studies [40-42] and can be explained as the result of the previously cited acid-catalyzed esterification reaction [43]. Concerning the total amount of esters, Merlot is notable for having experienced a slight reduction during the 12 months in wine closed with a conventional stopper, whereas the Merlot, Lagrein rosé, Lagrein red and St. Magdalener wines closed with the 'blend' stopper showed a higher total ester content at the end of the storage compared to the start of the storage. This latter trend can occur as a consequence of the esterification of branched acids to form ethyl esters [44-46].

In order to assess further relations between the type of stopper and the volatile compounds, PCA was applied to all of the red and rose wine samples, the volatile compounds and the dissolved oxygen levels detected during the storage period. The loadings and variables of the PCA are displayed in Figure 2.

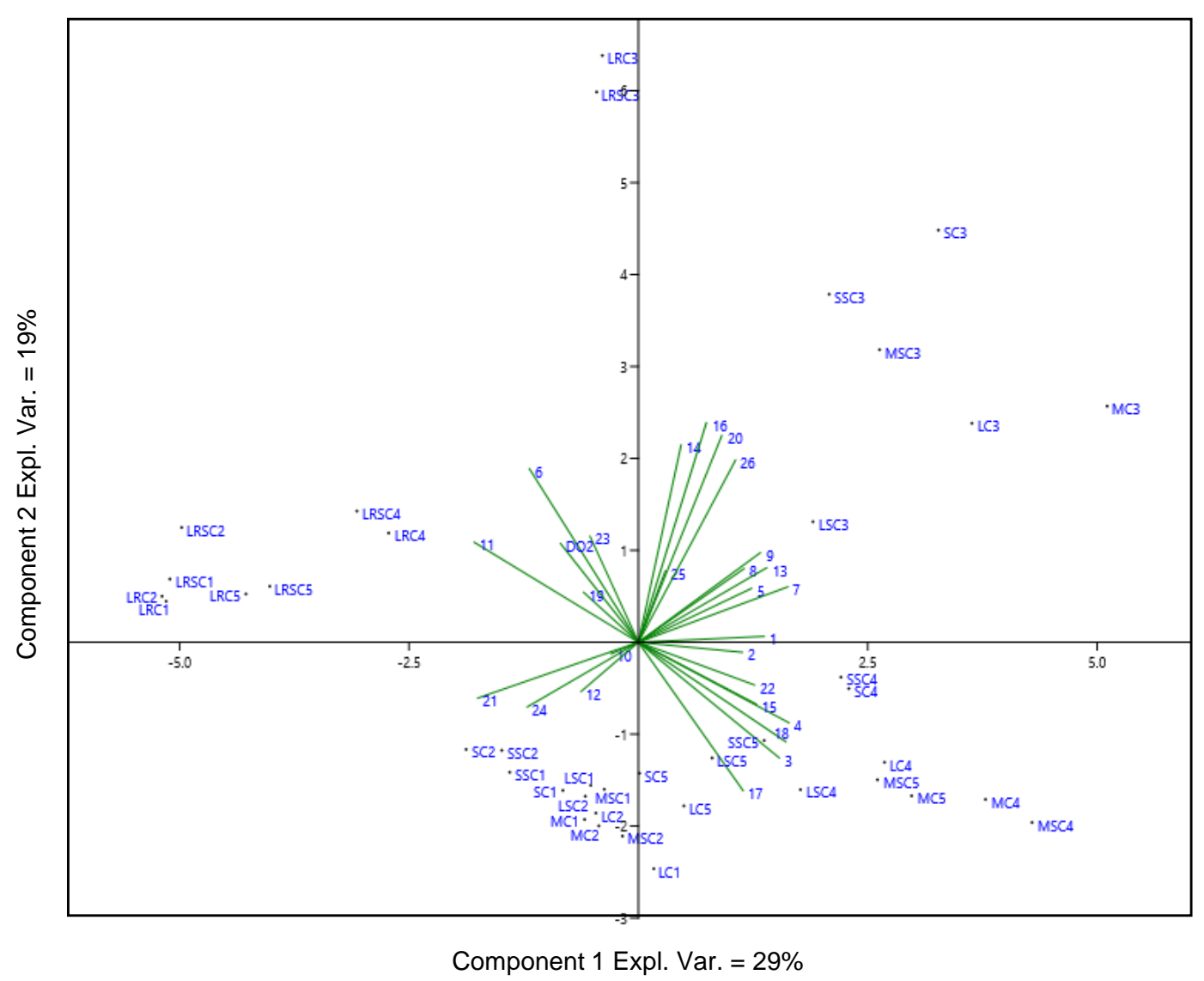

Figure 2. PCA bi-plot (PC-1 29\%, PC-2 19\%) of the three red wines and the rosé wine closed with different stoppers considering the volatile profiles and the dissolved oxygen $\left(\mathrm{DO}_{2}\right)$ during 12 months of bottle storage. Samples: LRC, LRSC, Lagrein rosé closed with conventional or 'blend' stopper, respectively. SC and SSC, St. Magdalener with conventional or 'blend' stopper. LC, LSC, same for Lagrein. MC, MSC, Merlot. Storage in bottle: $\mathbf{1}$, wine just after bottling; $\mathbf{2 , 3 , 4 , 5}$, wine analyzed one, three, six and 12 months after bottling, respectively. Volatile compounds are named 1-26 as listed in Table 4. 
The first two principal components explained $48 \%$ of the model (PC1, 29\%, PC2, 19\%). The PCA showed a separation of the rosé samples in the left part of the bi-plot with the T3 samples clustered away from all other samples along PC1. The red wines collected at bottling (T1) and after one month (T2) were grouped in the middle of the bi-plot, whereas samples stored for three months (T3) were segregated in the upper-right quadrant and samples collected after six months (T4) and 12 months (T5) were grouped together in the lower-right quadrant.

Some of the volatile compounds related to fresh fruity and floral notes, such as limonene (12), ethyl octanoate (21) and ethyl decanoate (24) positively correlated with samples stored for short periods (T1 and T2). On the other hand, a volatile compound connected with oxidation reaction such as diethyl succinate (18) distinguished samples stored for longer periods (T4 and T5). The rosé wine showed a positive correlation with 2-phenethyl acetate (23) and hexyl acetate (11); acetate esters are sensory descriptors of the fruity character of rosé wines [47]. Also, this PCA scattered the samples depending on the storage period, whereas there was a lack of differentiation among the bottles closed with the two stoppers. This explains the similar influence of the different stoppers on the volatile profiles and on the dissolved oxygen level during 12 months of storage.

No consistent significant difference in terms of stopper or time-stopper interaction was evidenced by two-way ANOVA for any wine in terms of specific variables, although some compounds showed differences at specific times for stoppers. The main significance was shown in relation to time evolution, which involved most of the volatile compounds for all wines, as shown for the phenolic compounds. These will be discussed in more details in relation to the sensory test results.

\subsection{Hierarchical Clustering Analysis (HCA)}

HCA was performed to assess the overall similarities and differences between the wines using the phenolic and volatile compounds identified as variables. The dendrogram clearly segregated the Lagrein rosé wine in a single branch of the diagram, separated from the three red wines (Figure 3).

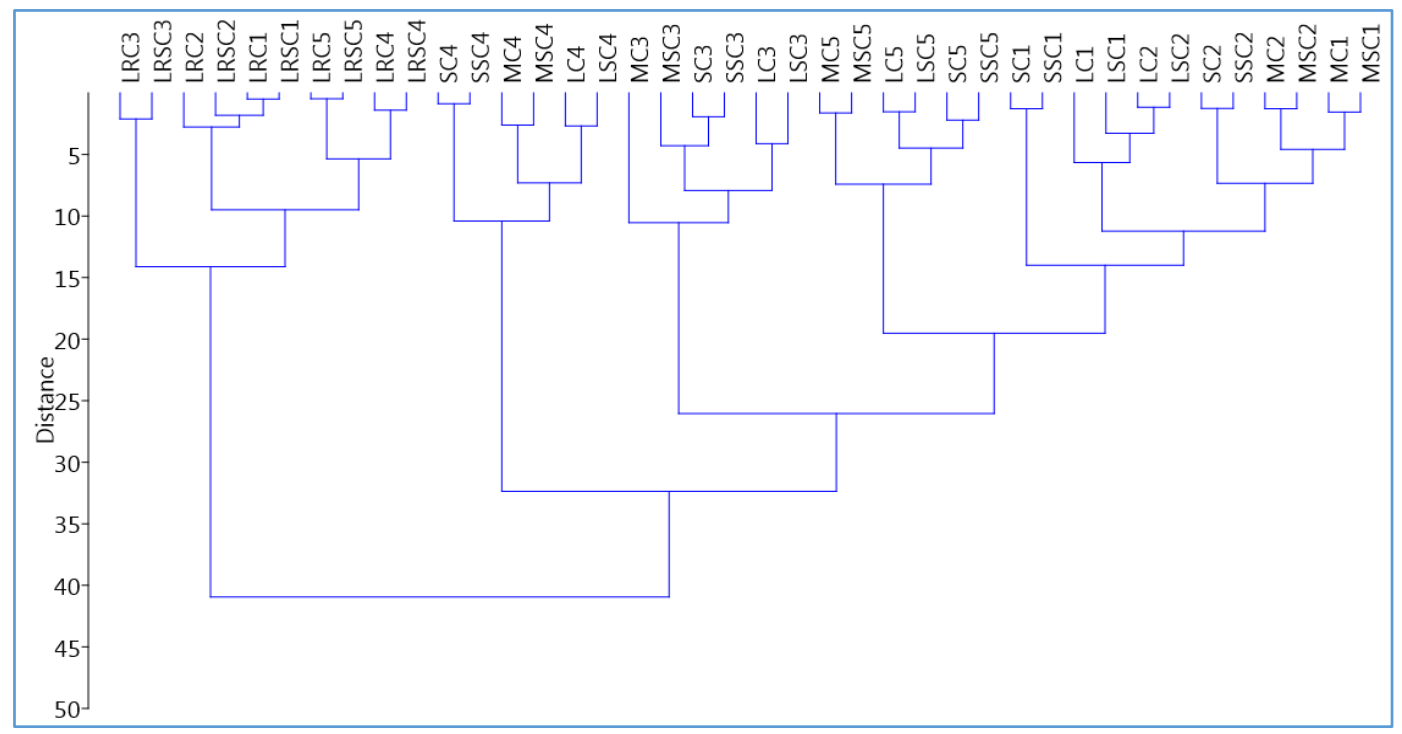

Figure 3. Hierarchical cluster analysis (HCA) of the four wines during 12 months of bottle storage. Samples: LRC, LRSC, Lagrein rosé closed with conventional or 'blend' stopper, respectively. SC and SSC, St. Magdalener with conventional or 'blend' stopper. LC, LSC, same for Lagrein. MC, MSC, Merlot. Storage in bottle: 1, wine just after bottling; 2,3,4,5, wine analyzed one, three, six and 12 months after bottling, respectively.

The Merlot, Lagrein red and St. Magdalener wines were clustered at a close hierarchical distance at $\mathrm{T} 1$ and T2, highlighting similarities to each other. Samples obtained after three and 12 months after bottling (T3 and T5) were segregated in two adjacent branches, whereas samples after six months 
bottling were isolated in an individual branch. This result shows that the evolution of the wines started after three months (T3), and reached the maximum differentiation after six months (T4). At 12 months of bottle storage, the composition of the wines changed again and became more similar to its initial state. Regarding the type of stopper, with HCA the wine bottles closed using the two conventional stoppers were at a close hierarchical distance, thus explaining the similar influence of similar stoppers on the phenolic and volatile profiles.

\subsection{Sensory Analysis}

The results of the discriminant triangle test (Table 5) showed significant differences for St. Magdalener and Merlot wines closed with the two different stoppers at the bottling time (T1), probably due to imperfect homogeneity of the wine in the bottling line. A significant number of assessors also recognized differences concerning Merlot wine in the tasting session performed after six months of storage (T4). Conversely, the required number of correct answers for differentiating the two samples closed with the different stoppers for any of the four wines was not obtained in the other tasting evaluations. An overall view of the tasting sessions highlights only few cases of significant differences. So, the differences were presumably due to the natural variability of the product.

Table 5. Triangle test. ns: not significant; *: significant $(p<0.05)$.

\begin{tabular}{ccccc}
\hline & Lagrein Red & Lagrein Rosé & Merlot & St. Magdalener \\
\hline T1 (Bottling time) & $\mathrm{ns}$ & $\mathrm{ns}$ & $*$ & $*$ \\
T2 (1 month) & $\mathrm{ns}$ & $\mathrm{ns}$ & $\mathrm{ns}$ & $\mathrm{ns}$ \\
T3 (3 months) & $\mathrm{ns}$ & $\mathrm{ns}$ & $\mathrm{ns}$ & $\mathrm{ns}$ \\
T4 (6 months) & $\mathrm{ns}$ & $\mathrm{ns}$ & $*$ & $\mathrm{~ns}$ \\
T5 (12 months) & $\mathrm{ns}$ & $\mathrm{ns}$ & $\mathrm{ns}$ & $\mathrm{ns}$ \\
\hline
\end{tabular}

Further investigations were performed to identify the compounds possibly responsible for the correct discrimination of St. Magdalener at T1 and Merlot wine at T1 and T4. A PCA model was built for St. Magdalener samples upon volatile compounds in order to identify the species most relevant for for the differentiation of the samples (Figure 4).

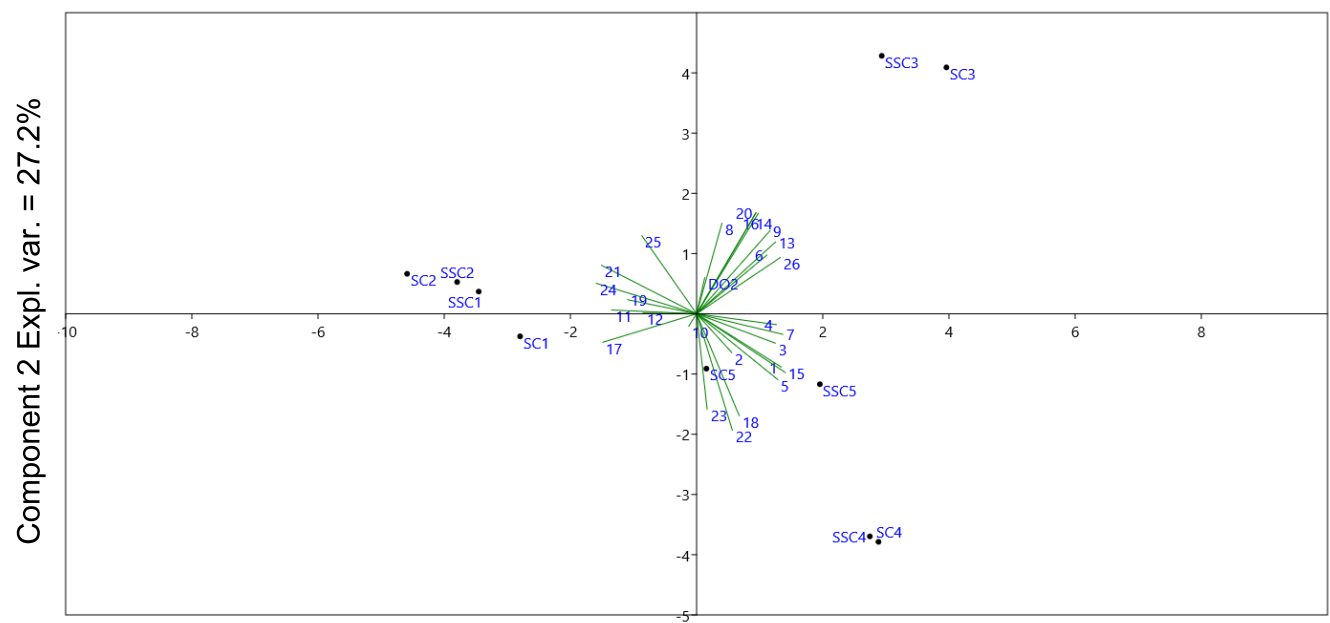

Component 1 Expl. var. $=40.8 \%$

Figure 4. PC1 (exp. variance $=40.8 \%)$ vs. PC2 (exp. variance $=27.2 \%)$ model for St. Magdalener wines. Volatile compound relative abundances and measured dissolved oxygen were used as variables. Volatile compound labels (1-26) are explained in Table 4.

The largest separation was identified between three groups of samples: T1-T2, T3 and T4, with T5 being more or less precisely at the center of the PCA model (considering PC1 and PC2). Two-way 
ANOVA was applied on all compounds to study the significance ( $p$-value $<0.05$ ) of the differences across the samples for specific variables, in particular with respect to the time evolution between stoppers and their interaction. Significant differences for the stopper were found for 2-ethylhexanol (13, $p$-value $\sim 0.05), 1$-octanol $(15, p$-value $\sim 0.05)$. Significant differences for time evolution were found for acetic acid (1), 1-hexanol (5), isopentyl acetate (6), 2-butyl 4-ethylbenzoate (7), 1-heptanol (8), 1-octen-3-ol (9), hexyl acetate (11), limonene (12), 2-ethylhexanol (13), methyl benzaldehyde (14), 1-octanol (15), ethyl benzaldehyde (16), 2-phenylethanol (17), diethyl succinate (18), octanoic acid (19), methyl salicylate (20), ethyl octanoate (21), ethyl benzeneacetate (22), 2-phenyl acetate (23), ethyl decanoate (24), ethyl dodecanoate (25) and ethyl hexadecanoate (26). No significant interaction between the two factors was found.

Only borderline differences (at $p$-value 0.05) were observed for the type of stopper. ANOVA indicated that the only significant differences observed between the samples were occurring as a time evolution, and in agreement with the interpretation of PC1 and PC2 in Figure 4. In fact, no variable was able to differentiate wines for the stoppers at a specific time.

As done with St. Magdalener, a PCA model was built on Merlot samples upon volatile compounds in order to identify the volatiles most differentiating the wines by the stopper (Figure 5).

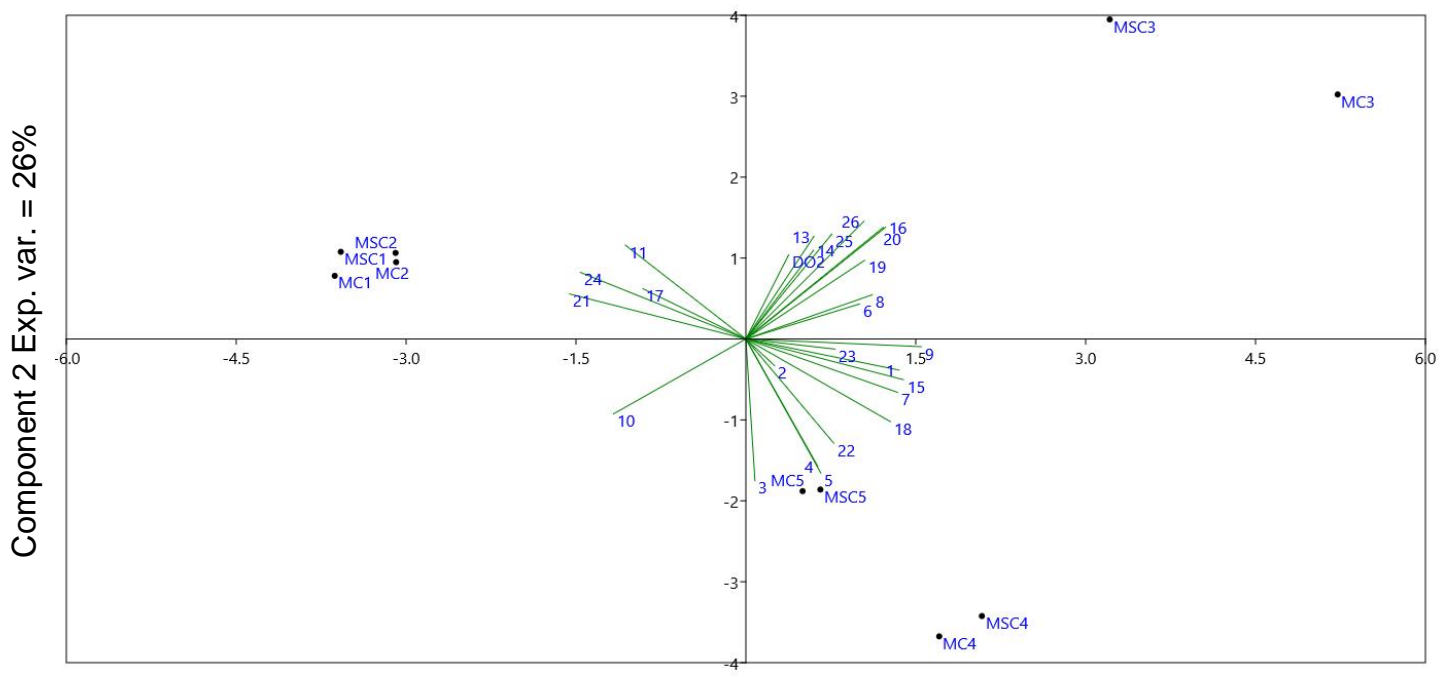

Component 1 Exp. var. $=38.7 \%$

Figure 5. PC1 (exp. variance $=38.7 \%)$ vs. $\mathrm{PC} 2($ exp. variance $=26 \%)$ model for Merlot wines. Volatile compound relative abundances and measured dissolved oxygen were used as variables. Volatile compounds labels (1-26) are explained in Table 4.

$\mathrm{T} 1$ and $\mathrm{T} 2$ samples were tightly clustered at negative values of PC1 and PC2. T3 samples were found at the highest positive values of $\mathrm{PC} 1$ and $\mathrm{PC} 2$, while at the same time completely separate from all other samples. T4 samples were found at the most negative values of PC2, whereas T5 samples were grouped in the same general direction, although much closer to the center of the PCA model with respect to both principal components. T4 samples showed again (as for St. Magdalener) to be between T3 and T5 with respect to PC1; similarly, the evolution from T3 to T5 appeared to opposed that from $\mathrm{T} 1$ to $\mathrm{T} 3$ along PC1. The separation of $\mathrm{T} 4$ from $\mathrm{T} 3$ and $\mathrm{T} 5$ occurred along PC2, but T3 samples were farther away than $\mathrm{T} 5$ in that direction, therefore indicating that these $\mathrm{T} 4$ samples could be regarded as a turning point in the wine evolution, with respect to the variables most relevant for PC2. Two-way ANOVA was applied to investigate the significance $(p$-value $<0.05)$ of differences for the time evolution, stoppers and possible factor interactions. As a result, significant differences (s.d.) were found with respect to the stopper for ethyl butanoate (2; $p$-value 0.05), methyl benzaldehyde (14), 1-octanol (15), octanoic acid (19) and methyl salicylate (20). 
Significant differences with respect to time were found for ethyl 2-methylbutanoate (3), ethyl 3-methylbutanoate (4), 1-hexanol (5), isopentyl acetate (6), 2-butyl 4-ethylbenzoate (7), 1-heptanol (8), ethyl hexanoate (10), 2-ethylhexanol (13), 4-methylbenzaldehyde (14), 1-octanol (15), 4-ethylbenzaldehyde (16), diethyl succinate (18), octanoic acid (19), methyl salicylate (20), ethyl octanoate (21), ethyl benzeneacetate (22), ethyl decanoate (24), ethyl dodecanoate (25) and ethyl tetradecanoate (26). Significant interactions between time and stopper were found for ethyl butanoate (2), 4-methylbenzaldehyde (14), 1-octanol (15), octanoic acid (19) and methyl salicylate (20). These were the same compounds differentiating the wines for stoppers. A Tukey's HSD test highlighted how several differences were found for time between the two stoppers (hence the interaction), but also that all these compounds differentiated the wines at T3 between the two stoppers. The main differences were seen overtime. In particular, no specific compound could be indicated as responsible for the difference between the two stoppers at T4. Further, as seen in Tables 1 and 2 and Section 3, the phenolic compounds' profiles (anthocyanins and non-anthocyanins) did not account for the differences observed in the triangle tests; instead, they mostly showed a dependence on storage time in the PCA (Figure 1), with the largest differences at T3 for all wines, mostly due to storage time, with few exceptions. Therefore, further investigations (especially in terms of descriptive sensory analysis and quantitative sensory models) will be therefore required in order to be correlated to the parallelly studied chemical profiles.

\section{Discussion}

This work explores the influence of type of stopper and storage period on the phenolic and volatile profiles of less-studied red and rosé wines from Lagrein and Schiava/Vernatsch red grape varieties during 12 months of bottle storage. Further information on the evolution of the phenolic and volatile compounds in these three red and one rosé wines from Northern Italy has been provided.

The total phenolic content clearly decreased during the bottle storage, with a remarkable loss recorded between six and 12 months, as observed in previous studies on a Cabernet Sauvignon [18] and at 10 months of bottle storage in a rosé wine from Grenache grapes [4]. Epicatechin, non-acetylated anthocyanins, acetylated anthocyanins and coumaroylated anthocyanins were those compounds showing the highest inverse correlation with the change from T1 to T5 (i.e., decreasing over time), and thus the most likely to undergo oligomerization reactions. The non-oxygen mediated nature of this transformation is also supported by the fact that the variation in the amount of dissolved oxygen was completely not correlated with the evolution of these variables from T1 to T5 in the PCA model built on the phenolic compounds.

Over 12 months of storage, changes in the volatile profiles resulted in lower concentrations of higher alcohols in all the four wines, as reported in previous studies [40-42]. Concerning the total amount of esters, Lagrein rosé, Lagrein red and St. Magdalener wines closed with the 'blend' stopper showed a higher abundance at the end of the storage compared to the beginning. A similar increasing trend was reported for the majority of ester compounds in Cabernet Sauvignon stored in bottles for nine months [23].

In conclusion, the present study shows that the type of stopper did not consistently influence the chemical profile evolution of the four wines. Only in few cases was a correlation observed in the evolution of the volatile compounds, although not in a consistent way. This study shows instead the time evolution of the four wines. Considering the low levels of dissolved oxygen, the changes detected in the phenolic and volatile concentrations were presumably due to non-oxygen-mediated reactions occurring during the 12 months of bottle storage, and in fact for the volatile profile they mainly involved ester formations.

Time evolutions were observed for all wines and involved most of the chemical variables identified. These results agree with previous studies outlining no significant differences due to type of stopper on the evolution of chemical and sensory profiles [20]. However, this observation may still be related to the type of wine studied, as some exceptions are present in previous works for synthetic, screw-cap and glass closures vs. natural cork closures for Chardonnay wines [2]. As recently reviewed [18], 
control over wine exposure to oxygen during and after bottling operations is required to positively influence the desired evolution of chemical and sensory profiles, although these will strongly evolve depending on the type of wine. Further studies may consider drawing a model that more closely relates the sensory and chemical profiles, as well as extending the investigation beyond 12 months to assess major influences of the different stoppers on the evolutions of phenolic and volatile profiles.

\section{Materials and Methods}

\subsection{Wine Samples and Stoppers}

Four Italian wines were provided by a winery located in South Tyrol (Kellerei Bozen, Bolzano, Italy). Merlot and Lagrein red and Lagrein rosé wines were obtained only from the corresponding local grapes (monovarietal wines), whereas the St. Magdalener wine was a blend obtained from Schiava (dominant) and Lagrein grape varieties. All the grapes were harvested in 2016 from vineyards located in the South Tyrol area, and the wines were bottled within the following year. The winery provided a total number of 80 bottles $(0.75 \mathrm{~L})-20$ bottles for each type of wine. The wine bottles were sealed with different stoppers, and a stopper consisting of a sanitized cork micro-granule blend of natural cork with polymers without the addition of glue to the mix ('blend' stopper, Supercap srl, Mombaroccio, Italy) was compared with three different types of stopper (one-piece natural cork, agglomerated natural cork, technical cork 1+1) according to the scheme outlined in Table 6 . The bottles were stored horizontally and protected from light, first at a cellar temperature, then in a laboratory with constant controlled temperature $\left(23^{\circ} \mathrm{C}\right)$ and medium relative humidity. The analyses were performed at five specific time points: at bottling (T1), after one month (T2), at three months (T3), at six months (T4) and at 12 months (T5) of storage at cellar temperature. At each sampling time, four bottles of each wine (two bottles closed with the same stopper, thus two replicates for each stopper type) were analyzed.

Table 6. Types of closures used for the wine bottles.

\begin{tabular}{ccc}
\hline Wines & Control & Conventional Stoppers \\
\hline Lagrein red & Blend ${ }^{\text {a }}$ & One-piece natural cork \\
Lagrein Rosé & Blend & Technical cork $1+1$ \\
Merlot & Blend & Technical cork $1+1$ \\
St Magdalener & Blend & Agglomerated natural cork \\
\cline { 2 - 3 } a Sanitized cork & micro-granule blend of natural cork with polymers and without the addition of glue to the mix.
\end{tabular}

\subsection{Chemicals and Reagents}

All reagents and chemical standards used in this study were purchased from Sigma-Aldrich S.p.A. (Milan, Italy), whereas the solvents (analytical grade) were obtained from VWR International s.r.l. (Milan, Italy).

\subsection{Non-Anthocyanin Phenolic Compounds}

The analysis of the non-anthocyanin polyphenols (phenolic acids, flavan-3-ols, stilbenes) was performed through a UHPLC-DAD-HRMS system (Agilent 1290 Infinity, Les Ulis, France) equipped with a UV-Vis diode array detector (DAD) (1290 Infinity) connected to the quadrupole time of a flight mass spectrometer (QToF/MS) with an electrospray ionization (ESI) source (Agilent 6530 Agilent Accurate Mass). The UHPLC-DAD-HRMS analyses were carried out on a C18 reversed-phase column $(2.1 \times 100 \mathrm{~mm}, 1.8 \mu \mathrm{m}$, Agilent). Samples were directly filtered on a $0.45-\mu \mathrm{m}$-membrane filter before the injection. The temperature of the column was $25^{\circ} \mathrm{C}$ and the flow rate was set to $0.3 \mathrm{~mL} / \mathrm{min}$, with the injection volume set at $2.0 \mu \mathrm{L}$. The mobile phases consisted of (A) aqueous $0.1 \%$ formic acid and (B) methanol with an addition of $0.1 \%$ formic acid. The gradient of solvent $\mathrm{B}$ was as follows: $6 \%$ for $0.5 \mathrm{~min}$, $6 \%$ to $40 \%$ for $29.5 \mathrm{~min}, 40 \%$ to $100 \%$ for $8 \mathrm{~min}, 100 \%$ for $5 \mathrm{~min}$ and back to $6 \%$ in $2 \mathrm{~min}$, followed by washing and re-equilibration for $3 \mathrm{~min}$. The mass spectrometer was operated in the extended dynamic 
range of $2 \mathrm{GHz}\left(\mathrm{m} / \mathrm{z}\right.$ 3200). The nebulizer pressure and flow rate were set at $25 \mathrm{psi}$ and $9 \mathrm{~L} \mathrm{~min}^{-1}$, respectively. Its drying gas temperature was $300^{\circ} \mathrm{C}$. The sheath gas flow and temperature were set at $11 \mathrm{~L} \mathrm{~min}^{-1}$ and $350^{\circ} \mathrm{C}$. The fragmentation, skimmer, OCT and capillary voltage were set at 150, 65, 750 and $4000 \mathrm{~V}$, respectively. The analyses were performed in negative ionization mode. The data analysis was performed on Mass Hunter Qualitative Analysis software (version B.06.00). Phenolic compounds were identified by comparing their chromatographic retention times and accurate masses with those of pure standard compounds. The calibration curves of pure standard substances were established through the DAD and were used to quantify the phenolic concentrations. When reference compounds were not available, a calibration with structurally related standard substances was used (gallic acid for protocatechuic acid and syringic acid; caffeic acid for caftaric acid and glutathionyl caftaric acid (GRP); (+)-catechin for (-)-epicatechin). The integrated peaks were allowed to obtain the concentrations of the identified compounds. Concentrations were expressed in $\mathrm{mg} \mathrm{L}^{-1}$ of standard or of the structurally related standard.

\subsection{Anthocyanins}

The relative composition of three anthocyanins classes (glucosides, acetyl-glucosides and coumaroyl-glucosides) was determined using a method slightly modified from [48]. Samples were directly filtered on a $0.45-\mu \mathrm{m}$-membrane filter before analysis. The HPLC system (Accela series, Thermo-Scientific, Illkirch-Graffenstaden, France) was equipped with a $4 \times 250 \mathrm{~mm}$ internal diameter (i.d.), 5- $\mu \mathrm{m}$ Nucleosil C18 column (Agilent). The solvents used were water (Eluent A) and acetonitrile (Eluent B), both containing 5\% formic acid. The gradient of solvent B consisted of $10 \%-23 \%$ in $16 \mathrm{~min}$, $23 \%-28 \%$ in $19 \mathrm{~min}$ and $28 \%-100 \%$ in $6 \mathrm{~min}$ at a flow rate of $1 \mathrm{~mL} / \mathrm{min}$. The column was washed with $100 \%$ acetonitrile for $5 \mathrm{~min}$ and re-equilibrated with the initial conditions for $3 \mathrm{~min}$ [49]. The tentative identification of the analytes was performed in accordance with bibliographic data. The quantification was carried out through the injection of malvidin-3-O-glucoside (Mv3G) as an external standard.

\subsection{Volatile Compounds}

The profile of the volatile compounds was obtained by gas-chromatography mass-spectrometry (GC-MS) after extraction with head-space solid-phase micro-extraction (HS-SPME) according to a published procedure [50], with slight modifications. Briefly, $10 \mathrm{~mL}$ of wine were introduced into a $20-\mathrm{mL}$ vial and $1 \mathrm{~g} \mathrm{NaCl}$ was added. After mixing, the vial was tightly capped with a screw cap equipped with a perforable elastomeric septum. The vial was equilibrated in a heating bath at $40{ }^{\circ} \mathrm{C}$ for $10 \mathrm{~min}$. Afterwards, a SPME fiber coated with 50/30 $\mu \mathrm{m}$ divinylbenzene/carboxen/polydimethylsiloxane (DVB/CAR/PDMS; Supelco/Sigma-Aldrich, Milan, Italy) was inserted into the vial and exposed to the sample headspace for 20 min under continuous heating. Subsequently, the thermal desorption took place in the GC injector at $220^{\circ} \mathrm{C}$ for $3 \mathrm{~min}$. A Varian 3900 gas-chromatograph coupled to a Saturn 2100T (Varian, Walnut Creek, CA, USA) ion trap mass spectrometer was equipped with a ZB-5 capillary column (Phenomenex, $30 \mathrm{~m} \times 0.25 \mathrm{~mm}$ I.D., film thickness $0.25 \mu \mathrm{m}$ ). The injection was in splitless mode (splitless time $0.3 \mathrm{~min}$ ) and the temperature program of the GC oven was conducted as follows:

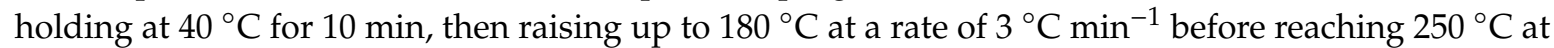
$15^{\circ} \mathrm{C} \mathrm{min}^{-1}$. The MS transfer line and trap temperatures were set at $200^{\circ} \mathrm{C}$. The ion trap emission current was $10 \mu \mathrm{A}$. The mass spectra were recorded in the full scan mode (mass range 31-250 m/z) at 1 scan s $^{-1}$. Data were analyzed with the Varian Workstation software. Tentative identification was based on the comparison with the NIST library mass spectra (Version: 2.0; 2002), the GC linear retention indices reported in the literature and through the injection of pure standard substances [51], when available. Samples were analyzed in duplicate (two different bottles for each stopper type). Quantification of the peaks area was expressed as an internal area percentage. 


\subsection{Dissolved Oxygen Content}

The dissolved oxygen content of the wines was measured using a non-invasive optical L.sensor$700 . \mathrm{O}_{2}$ (FT system, Alseno, Italy). The technology used an IR laser type; the range of the measurement was between $0.3 \%$ and $21 \% \mathrm{O}_{2} \pm 0.3 \%$; the accuracy was $\pm 0.2 \%$ (oxygen concentration).

\subsection{Sensory Analysis}

A sensory panel (10 women and eight men, ages 23-60 years) was formed by professional wine judges from the enology research unit of the Institut de Science de la Vigne et du Vin (ISVV, Bordeaux, France). The sensory sessions were conducted in a tasting room provided with individual booths according to the ISO 8589 at the same research unit (ISVV).

The discriminant triangle test (ISO 4120: 2007) was chosen to evaluate the possible differences between each of the four wines closed with a conventional cork stopper and compared to the 'blend' stopper at each storage time. The sensitivity parameters of the test were set at $\alpha=0.5, \beta=0.20$ and $p_{\mathrm{d}}=50 \%$.

The judges received four sets of three wines and were asked to evaluate each set per time selecting the odd sample of each set. The glasses were labeled with three-digit random codes and were presented to the panelists according to a random order, as prescribed by the standard methodology for the triangle test in sensory analysis (ISO 4120:2007). Each session was one day after the first.

\subsection{Statistical Analysis}

All the chemical data refer to the determination of two replicate bottles for each type of stopper, and each of the four types of wine were sampled at each of the five time intervals (T1-T5). For the volatile compounds, data are reported as internal area averages of the two replicates with the related standard deviation. Two-way analysis of variance (two-way ANOVA) was performed using GraphPad Prism v6.01 software (San Diego, CA, USA) with the storage time and stopper type as independent variables. When significant differences were revealed $(p<0.05)$, a Tukey's (HSD) multiple comparison test was applied to compare the mean concentrations.

A Student's $t$-test was applied to compare the dissolved oxygen concentrations into the wines closed with the comparative stoppers $(p<0.05)$.

Multivariate statistics was applied to the normalized data of the phenolic and volatile profiles. Hierarchical cluster analysis (HCA) was performed to assess the similarities among the wines employing Euclidean distance and Ward's linkage method. Principal component analysis (PCA) was carried out to evaluate the influence of phenols and volatiles on the wines closed with the different stoppers. PCA and HCA were both performed using PAST software v3.18 [52]. The sensory data obtained from the triangle test sessions were analyzed according to the ISO 4120—Sensory analysis—Methodology.

Supplementary Materials: The following are available online. Tables S1: Tables of volatile compounds average peak areas in the studied wines.

Author Contributions: Conceptualization, F.R., M.J., P.-L.T., R.F., E.L. and E.B.; Data curation, F.R., A.J., M.J., P.-L.T., R.F. and E.L.; Formal analysis, F.R., P.-L.T. and E.L.; Funding acquisition, E.B.; Investigation, F.R., A.J., M.J., R.F. and E.L.; Methodology, F.R., A.J., M.J., P.-L.T., E.L. and E.B.; Project administration, E.B.; Resources, M.J., P.-L.T. and E.B.; Supervision, M.J., P.-L.T. and E.B.; Validation, M.J. and E.L.; Visualization, E.L.; Writing-original draft, F.R.; Writing-review \& editing, M.J., P.-L.T., E.L. and E.B. All authors have read and agreed to the published version of the manuscript.

Funding: This project has been funded by the Oenolab Start-up Project (TN2810) and the WineID Project (TN201A) of the Free University of Bozen-Bolzano. This work was supported by the Open Access Publishing Fund of the Free University of Bozen-Bolzano.

Acknowledgments: We thank Kellerei Bozen (Bolzano, Italy) for providing the wines used in this experimentation and for the collaboration in the sampling procedure. We thank Supercap srl (Mombaroccio, Italy) for providing the stoppers (blend of natural cork microgranules and synthetic polymers) used in this work. F. Rossetti has been supported by the Erasmus Programme during his study and research period at the University of Bordeaux, France. The panelists of the Universities of Bordeaux are kindly acknowledged. 
Conflicts of Interest: The authors declare no conflict of interest. The funders had no role in the design of the study; in the collection, analyses, or interpretation of data; in the writing of the manuscript, or in the decision to publish the results.

\section{References}

1. Ribéreau-Gayon, P.; Glories, Y.; Maujean, A.; Dubourdieu, D. Handbook of Enology-The Chemistry of Wine Stabilization and Treatments; John Wiley \& Sons, Ltd.: Chichester, UK, 2006.

2. Skouroumounis, G.; Kwiatkowski, M.; Francis, I.; Oakey, H.; Capone, D.; Duncan, B.; Sefton, M.; Waters, E. The impact of closure type and storage conditions on the composition, colour and flavour properties of a Riesling and a wooded Chardonnay wine during five years' storage. Aust. J. Grape Wine Res. 2005, 11, 369-377. [CrossRef]

3. Puškaš, V.; Miljić, U.D. The application of D-optimal design for modelling the red wine ageing process. Food Control. 2012, 28, 362-367. [CrossRef]

4. Wirth, J.; Morel-Salmi, C.; Souquet, J.M.; Dieval, J.; Aagaard, O.; Vidal, S.; Fulcrand, H.; Cheynier, V. The impact of oxygen exposure before and after bottling on the polyphenolic composition of red wines. Food Chem. 2010, 123, 107-116. [CrossRef]

5. Somers, T. The polymeric nature of wine pigments. Phytochemistry 1971, 10, 2175-2186. [CrossRef]

6. Escudero, A.; Asensio, E.; Cacho, J.; Ferreira, V. Sensory and chemical changes of young white wines stored under oxygen. An assessment of the role played by aldehydes and some other important odorants. Food Chem. 2002, 77, 325-331. [CrossRef]

7. Mozzon, M.; Savini, S.; Boselli, E.; Thorngate, J. The herbaceous character of wines. Italy J. Food Sci. 2016, 28, 190-207.

8. De Souza, J.F.; Nascimento, A.M.D.S.; Linhares, M.D.S.S.; Dutra, M.D.C.P.; Lima, M.D.S.; Pereira, G.E. Evolution of Phenolic Compound Profiles and Antioxidant Activity of Syrah Red and Sparkling Moscatel Wines Stored in Bottles of Different Colors. Beverages 2018, 4, 89. [CrossRef]

9. Lopes, P.; Saucier, C.; Teissedre, P.-L.; Glories, Y. Impact of storage position on oxygen ingress through different closures into wine bottles. J. Agric. Food Chem. 2006, 54, 6741-6746. [CrossRef]

10. Lopes, P.; Saucier, C.; Teissedre, P.-L.; Glories, Y. Main Routes of Oxygen Ingress through Different Closures into Wine Bottles. J. Agric. Food Chem. 2007, 55, 5167-5170. [CrossRef]

11. Diéval, J.-B.; Vidal, S.; Aagaard, O. Measurement of the Oxygen Transmission Rate of Co-extruded Wine Bottle Closures Using a Luminescence-Based Technique. Packag. Technol. Sci. 2011, 24, 375-385. [CrossRef]

12. Godden, P.; Francis, L.; Field, J.; Gishen, M.; Coulter, A.; Valente, P.; Høj, P.; Robinson, E. Wine bottle closures: Physical characteristics and effect on composition and sensory properties of a Semillon wine 1. Performance up to 20 months post-bottling. Aust. J. Grape Wine Res. 2001, 7, 64-105. [CrossRef]

13. Boselli, E.; Di Lecce, G.; Alberti, F.; Frega, N.G. Nitrogen gas affects the quality and the phenolic profile of must obtained from vacuum-pressed white grapes. LWT 2010, 43, 1494-1500. [CrossRef]

14. Day, M.; Schmidt, S.A.; Smith, P.; Wilkes, E. Use and impact of oxygen during winemaking. Aust. J. Grape Wine Res. 2015, 21, 693-704. [CrossRef]

15. Trivellin, N.; Barbisan, D.; Badocco, D.; Pastore, P.; Meneghesso, G.; Meneghini, M.; Zanoni, E.; Belgioioso, G.; Cenedese, A. Study and Development of a Fluorescence Based Sensor System for Monitoring Oxygen in Wine Production: The WOW Project. Sensors 2018, 18, 1130. [CrossRef] [PubMed]

16. Silva, A.; Lambri, M. Oxygen measures and consumption in must and wine. Anal. Chim. Acta 2006, 563, 391-395. [CrossRef]

17. Crouvisier-Urion, K.; Bellat, J.-P.; Gougeon, R.D.; Karbowiak, T. Gas transfer through wine closures: A critical review. Trends Food Sci. Technol. 2018, 78, 255-269. [CrossRef]

18. Silva, M.A.; Julien, M.; Jourdes, M.; Teissedre, P.-L. Impact of closures on wine post-bottling development: A review. Eur. Food Res. Technol. 2011, 233, 905-914. [CrossRef]

19. Gao, Y.; Tian, Y.; Liu, D.; Li, Z.; Zhang, X.-X.; Li, J.; Huang, J.-H.; Wang, J.; Pan, Q.-H. Evolution of phenolic compounds and sensory in bottled red wines and their co-development. Food Chem. 2015, 172, 565-574. [CrossRef] 
20. Xing, R.-R.; Liu, D.; Li, Z.; Tian, Y.; Zhang, X.-X.; Li, J.-M.; Pan, Q.-H. Impact of different types of stoppers on sensorial and phenolic characteristics evolution during a bottle storage time of a white wine from Chardonnay grape variety. J. Food Sci. Technol. 2016, 53, 4043-4055. [CrossRef]

21. Sáenz-Navajas, M.-P.; Avizcuri, J.-M.; Ferreira, V.; Fernandez-Zurbano, P. Sensory changes during bottle storage of Spanish red wines under different initial oxygen doses. Food Res. Int. 2014, 66, 235-246. [CrossRef]

22. Ugliano, M. Oxygen Contribution to Wine Aroma Evolution during Bottle Aging. J. Agric. Food Chem. 2013, 61, 6125-6136. [CrossRef] [PubMed]

23. Liu, D.; Xing, R.-R.; Li, Z.; Yang, D.-M.; Pan, Q.-H. Evolution of volatile compounds, aroma attributes, and sensory perception in bottle-aged red wines and their correlation. Eur. Food Res. Technol. 2016, 242, 1937-1948. [CrossRef]

24. Castellari, M.; Matricardi, L.; Arfelli, G.; Galassi, S.; Amati, A. Level of single bioactive phenolics in red wine as a function of the oxygen supplied during storage. Food Chem. 2000, 69, 61-67. [CrossRef]

25. Cheynier, V.; Rigaud, J.; Souquet, J.; Duprat, F.; Moutounet, M. Must browning in relation to the behaviour of phenolic compounds during oxidation. Am. J. Enol. Vitic. 1990, 41, 346-349.

26. Gómez-Plaza, E.; Gil-Muñoz, R.; López-Roca, J.; Martínez-Cutillas, A.; Fernández-Fernández, J. Maintenance of Colour Composition of a Red Wine during Storage. Influence of Prefermentative Practices, Maceration Time and Storage. LWT 2002, 35, 46-53. [CrossRef]

27. Zafrilla, P.; Morillas, J.; Mulero, J.; Cayuela, J.M.; Martínez-Cachá, A.; Pardo, F.; López-Nicolás, J. Changes during Storage in Conventional and Ecological Wine: Phenolic Content and Antioxidant Activity. J. Agric. Food Chem. 2003, 51, 4694-4700. [CrossRef] [PubMed]

28. Klesk, K.; Qian, M. Aroma Extract Dilution Analysis of Cv. Marion (Rubusspp.hyb) and Cv. Evergreen (R. laciniatus L.) Blackberries. J. Agric. Food Chem. 2003, 51, 3436-3441. [CrossRef] [PubMed]

29. Kim, T.H.; Shin, J.H.; Yu, E.J.; Kim, Y.-S.; Lee, H.J.; Kim, T.H. Characteristics of aroma-active compounds in the pectin-elicited suspension culture of Zanthoxylum piperitum (prickly ash). Biotechnol. Lett. 2002, 24, 551-556. [CrossRef]

30. Beaulieu, J.C.; Grimm, C.C. Identification of volatile compounds in cantaloupe at various developmental stages using solid phase microextraction. J. Agric. Food Chem. 2001, 49, 1345-1352. [CrossRef]

31. Xu, X.; Stee, L.L.P.; Williams, J.; Beens, J.; Adahchour, M.; Vreuls, R.J.J.; Brinkman, U.A.; Lelieveld, J. Comprehensive two-dimensional gas chromatography $(\mathrm{GC} \times \mathrm{GC})$ measurements of volatile organic compounds in the atmosphere. Atmos. Chem. Phys. Discuss. 2003, 3, 665-682. [CrossRef]

32. Schirack, A.; Drake, M.; Sanders, T.; Sandeep, K. Characterization of Aroma-Active Compounds in Microwave Blanched Peanuts. J. Food Sci. 2006, 71, C513-C520. [CrossRef]

33. Su, Y.-C.; Ho, C.L.; Wang, E.I.-C.; Chang, S.-T. Antifungal activities and chemical compositions of essential oils from leaves of four eucalypts. Taiwan J. Sci. 2006, 21, 49-61.

34. Flamini, G.; Cioni, P.L.; Morelli, I. Volatiles from Leaves, Fruits, and Virgin Oil fromOlea europaea Cv. Olivastra Seggianese from Italy. J. Agric. Food Chem. 2003, 51, 1382-1386. [CrossRef] [PubMed]

35. Boulanger, R.; Crouzet, J. Free and bound flavour components of Amazonian fruits 3-glycosidically bound components of cupuacu. Food Chem. 2000, 70, 463-470. [CrossRef]

36. Sampaio, T.S.; Nogueira, P.C.L. Volatile components of mangaba fruit (Hancornia speciosa Gomes) at three stages of maturity. Food Chem. 2006, 95, 606-610. [CrossRef]

37. Passos, X.S.; Castro, A.C.M.; Pires, J.S.; Garcia, A.C.F.; Campos, F.C.; Fernandes, O.F.L.; Paula, J.R.; Ferreira, H.D.; Santos, S.; Ferri, P.H.; et al. Composition and Antifungal Activity of the Essential Oils of Caryocar brasiliensis. Pharm. Boil. 2003, 41, 319-324. [CrossRef]

38. Moio, L.; Ugliano, M.; Genovese, A.; Gambuti, A.; Pessina, R.; Piombino, P. Effect of Antioxidant Protection of Must on Volatile Compounds and Aroma Shelf Life of Falanghina (Vitis vinifera L.) Wine. J. Agric. Food Chem. 2004, 52, 891-897. [CrossRef]

39. Ugliano, M.; Siebert, T.; Mercurio, M.; Capone, D.; Henschke, P.A. Volatile and Color Composition of Young and Model-Aged Shiraz Wines as Affected by Diammonium Phosphate Supplementation Before Alcoholic Fermentation. J. Agric. Food Chem. 2008, 56, 9175-9182. [CrossRef]

40. Culleré, L.; Cacho, A.J.; Ferreira, V. An Assessment of the Role Played by Some Oxidation-Related Aldehydes in Wine Aroma. J. Agric. Food Chem. 2007, 55, 876-881. [CrossRef]

41. Escudero, A.; Hernández-Orte, P.; Cacho, J.; Ferreira, V.; Hernández-Orte, P. Clues about the Role of Methional As Character Impact Odorant of Some Oxidized Wines. J. Agric. Food Chem. 2000, 48, 4268-4272. [CrossRef] 
42. Fedrizzi, B.; Zapparoli, G.; Finato, F.; Tosi, E.; Turri, A.; Azzolini, M.; Versini, G. Model Aging and Oxidation Effects on Varietal, Fermentative, and Sulfur Compounds in a Dry Botrytized Red Wine. J. Agric. Food Chem. 2011, 59, 1804-1813. [CrossRef]

43. Di Lecce, G.; Boselli, E.; D’Ignazi, G.; Frega, N.G. Evolution of phenolics and glutathione in Verdicchio wine obtained with maceration under reductive conditions. LWT 2013, 53, 54-60. [CrossRef]

44. Ferreira, V.; Escudero, A.; Fernández, P.; Cacho, J. Changes in the profile of volatile compounds in wines stored under oxygen and their relationship with the browning process. Z. Lebensm. Forsch. A 1997, 205, 392-396. [CrossRef]

45. Hernanz, D.; Gallo, V.; Fernández-Recamales, M.Á.; Meléndez-Martínez, A.J.; Gonzalez-Miret, M.; Heredia, F.J. Effect of storage on the phenolic content, volatile composition and colour of white wines from the varieties Zalema and Colombard. Food Chem. 2009, 113, 530-537. [CrossRef]

46. Makhotkina, O.; Pineau, B.; Kilmartin, P.A. Effect of storage temperature on the chemical composition and sensory profile of Sauvignon Blanc wines. Aust. J. Grape Wine Res. 2012, 18, 91-99. [CrossRef]

47. Wang, J.; Capone, D.L.; Wilkinson, K.; Jeffery, D.W. Rosé wine volatile composition and the preferences of Chinese wine professionals. Food Chem. 2016, 202, 507-517. [CrossRef]

48. Chira, K. In Structures Moléculaires et Perception Tannique Des Raisins et Des Vins (Cabernet-Sauvignon, Merlot) du Bordelais. Ph.D. Thesis, University of Bordeaux II, Bordeaux, France, 11 December 2009. Available online: http://www.sudoc.fr/14547027X (accessed on 16 September 2020).

49. Paissoni, M.A.; Waffo-Teguo, P.; Ma, W.; Jourdes, M.; Rolle, L.; Teissedre, P.-L. Chemical and sensorial investigation of in-mouth sensory properties of grape anthocyanins. Sci. Rep. 2018, 8, 17098. [CrossRef] [PubMed]

50. Rodrigues, F.; Caldeira, M.; Câmara, J. Development of a dynamic headspace solid-phase microextraction procedure coupled to GC-qMSD for evaluation the chemical profile in alcoholic beverages. Anal. Chim. Acta 2008, 609, 82-104. [CrossRef]

51. Mozzon, M.; Foligni, R.; Mannozzi, C. Brewing Quality of Hop Varieties Cultivated in Central Italy Based on Multivolatile Fingerprinting and Bitter Acid Content. Foods 2020, 9, 541. [CrossRef]

52. Hammer, Ø.; Harper, D.A.T.; Ryan, P.D. PAST: Paleontological statistics software package for education and data analysis. Palaeontol. Electron. 2001, 4, 9.

(C) 2020 by the authors. Licensee MDPI, Basel, Switzerland. This article is an open access article distributed under the terms and conditions of the Creative Commons Attribution (CC BY) license (http://creativecommons.org/licenses/by/4.0/). 